\title{
Metabolic Mapping of Suppression Scotomas in Striate Cortex of Macaques with Experimental Strabismus
}

\author{
Jonathan C. Horton, Davina R. Hocking, and Daniel L. Adams \\ Beckman Vision Center, University of California, San Francisco, San Francisco, California 94143-0730
}

Misalignment of the ocular axes induces double vision and rivalry. To prevent these unpleasant sensations, most subjects fixate preferentially with one eye and suppress entirely the deviating eye or else suppress portions of the visual field of either eye. To explore the mechanism of visual suppression, a divergent strabismus (exotropia) was induced in six normal, adult Macaca fascicularis by disinserting the medial rectus muscles. After 4-8 weeks, each animal was chaired to measure its exotropia and to determine its ocular fixation preference. Five of the monkeys developed a clearly dominant eye. It was injected with $\left[{ }^{3} \mathrm{H}\right]$ proline. Alternate sections from flat-mounts of striate cortex were then processed either for autoradiography to label the ocular dominance columns or for cytochrome oxidase (CO) to assess local metabolic activity. Two CO patterns were seen, often in the same cortex. The first consisted of thin dark columns alternating with wide pale columns. This pattern arose from reduced $\mathrm{CO}$ activity in the suppressed eye's monocular core zones and both eyes' binocular border strips. The second pattern consisted of thin pale bands from reduced metabolic activity in both eyes' border strips. The thin darkwide pale $\mathrm{CO}$ pattern was more widespread in the three animals with a strong fixation preference. The dark $\mathrm{CO}$ columns usually fit in register with the ocular dominance columns of the fixating eye, suggesting that perception was suppressed in the deviating eye. In most animals, however, the correlation switched in peripheral cortex contralateral to the deviating eye, implying local suppression of the fixating eye's temporal retina (beyond $10^{\circ}$ ), as reported in humans with divergent strabismus. In the two animals with a weak fixation preference, pale border strips were found within the central visual field representation in both hemispheres. This $\mathrm{CO}$ pattern was consistent with alternating visual suppression. These experiments provide the first anatomical evidence for changes in cortical metabolism that can be correlated with suppression scotomas in subjects with strabismus.

Key words: strabismus; scotoma; suppression; cytochrome oxidase; ocular dominance column; visual cortex; exotropia; border strip; core zone; stereopsis; binocular; diplopia
Understanding the phenomenon of visual suppression is one of the keys to solving the vexing problem of strabismus. Children who acquire strabismus rarely complain of diplopia (double vision), because they quickly adapt to misalignment of the ocular axes by suppressing vision from the deviating eye (von Noorden, 1996). Thus, visual suppression plays a critical role in the advent of strabismus by eliminating the drive to fuse disparate images. In addition, suppression often leads to amblyopia, if it becomes constant in one eye, rather than alternating between the eyes.

The mechanism of visual suppression in strabismus is unknown. It is not even clear whether visual suppression originates in primary visual cortex (striate cortex, V1), in extrastriate cortex, or at a subcortical level. Since the original report of Hubel and Wiesel (1965), numerous investigators have confirmed that strabismus reduces the number of cells in striate cortex that can be driven by both eyes. More recently, electrophysiological studies

Received April 28, 1999; revised June 7, 1999; accepted June 7, 1999.

This work was supported by National Eye Institute Grant RO1 EY10217 and Core Grant EY02162, That Man May See, and Research to Prevent Blindness. We thank Dr. Douglas R. Fredrick and Dr. Creig S. Hoyt for their help in evaluating the animals' ocular fixation preferences and Robin Troyer for assistance with animal care and surgery. We also thank the California Regional Primate Research Center (especially Dr. Celia Valverde, Jenny Short, and David Robb). The California Primate Center is supported by National Institutes of Health Base Grant RR00169. William T. Newsome, Arthur J. Jampolsky, Nélida B. Melek, and Anne K. Churchland provided valuable comments on this manuscript.

Correspondence should be addressed to Dr. Jonathan C. Horton, Beckman Vision Center, 10 Kirkham Street, University of California, San Francisco, San Francisco, CA 94143-0730.

Copyright (C) 1999 Society for Neuroscience $\quad 0270-6474 / 99 / 197111-19 \$ 05.00 / 0$ have uncovered the existence of inhibitory binocular interactions in animals raised with strabismus (Freeman and Tsumoto, 1983; Crewther and Crewther, 1993; Chino et al., 1994; Sengpiel and Blakemore, 1994; Smith et al., 1997). In these animals, the response of neurons to an optimal stimulus in one eye was suppressed by stimulation of the other eye. Such residual inhibitory interactions may contribute to strabismic suppression. Sengpiel and colleagues (1994) have suggested explicitly that strabismic suppression depends on inhibitory interactions between cells in neighboring ocular dominance columns.

Few studies have used anatomical methods to probe how strabismus alters the visual cortex. Löwel (1994) has reported that strabismus increases the width of ocular dominance columns in kittens, presumably by reducing the correlation of activity between eyes (Goodhill, 1993). In addition, it has been shown by intracortical tracer injections in strabismic animals that intrinsic tangential clustered connections are lost between ocular dominance columns serving opposite eyes (Löwel and Singer, 1992; Tychsen and Burkhalter, 1995). This loss of connections presumably reflects the breakdown of cortical binocularity that occurs from strabismus. It does not, however, shed any light on the problem of strabismic suppression. If anything, a loss of projections between ocular dominance columns serving the left eye and the right eye would reduce the substrate for interocular suppression, unless only facilitatory connections were attenuated.

The main objective of this study was to explore the phenomenon of strabismic suppression using the mitochondrial enzyme cytochrome oxidase $(\mathrm{CO})$ as a functional anatomical label. $\mathrm{CO}$ 


\section{Macaque Striate Cortex}

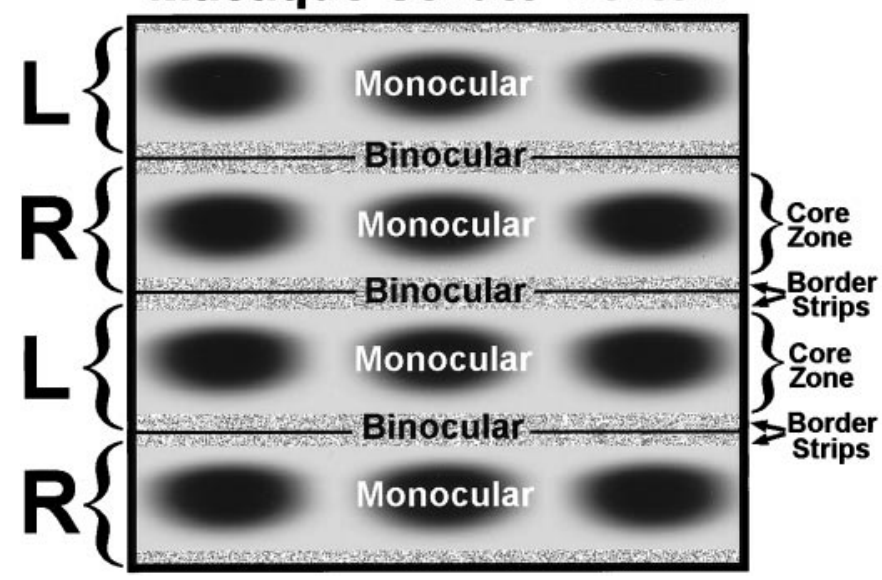

Figure 1. Schematic diagram of macaque striate cortex, drawn as if one were looking down through the cortical layers from the pial surface. On the left, brackets mark the actual boundaries of the ocular dominance columns in layer IVc $(L,=$ left; $R=$ right $)$. Each ocular dominance column contains a central, monocular core zone, with a row of $\mathrm{CO}$ patches (also known as "blobs" or "puffs") running down the middle. The CO patches are visible in all layers except IVc and IVa. Each monocular core zone is flanked by a thin binocular border strip. The border strips at the boundaries between ocular dominance columns create a single binocular region. Therefore, the existence of core zones and border strips gives rise to a regular system of alternating monocular and binocular compartments in striate cortex, at least within the representation of the central $12^{\circ}$ (beyond this eccentricity, the ocular dominance columns serving the ipsilateral eye become fragmented, and binocular function is reduced). Although sharp boundaries are shown, the transition between core zones and border strips is gradual. Our goal in this study was to test the effects of strabismus on $\mathrm{CO}$ activity in the core zones and the border strips serving each eye.

levels fluctuate dynamically with neuronal activity (Wong-Riley, 1994; DeYoe et al., 1995), making it an ideal label for this purpose. Our interest in strabismic suppression was kindled by the discovery that macaque striate cortex is subdivided into monocular core zones and binocular border strips (Horton, 1984; Horton and Hocking, 1998a). In normal animals, these compartments contain equal $\mathrm{CO}$ activity in layer IVc (Fig. 1). We reasoned that strabismus, by disrupting binocular function, might cause greater loss of $\mathrm{CO}$ in border strips than in core zones. We also predicted that animals with a strong fixation preference might lose $\mathrm{CO}$ activity in the core zones of their deviated eye, as a result of suppression. Our goal was to compare the fixation behavior of each animal with the pattern of $\mathrm{CO}$ activity in its visual cortex.

To avoid diplopia and conf usion, many subjects with strabismus appear to suppress information emanating from only part of the retina, instead of turning off the eye altogether. This phenomenon gives rise to local suppression scotomas, revealed when the visual fields are plotted dichoptically (Graefe, 1896). By unfolding striate cortex and stripping it from the white matter, one can prepare flattened sections containing the representation of the contralateral visual hemifield in a single piece of tissue (Horton and Hocking, 1996c). We hoped that by examining such flat-mounted sections from each hemisphere, we might find anatomical evidence for local suppression scotomas by correlating each animal's predominant fixation pattern with (1) the pattern of $\mathrm{CO}$ activity in its cortex, (2) the ocular dominance columns, and (3) the cortical map of the visual field.

\section{MATERIALS AND METHODS}

Experimental animals. We used six normal Macaca fascicularis imported from Mauritius in 1995. Their ages were unknown because they were feral animals. All were male, fully adult, weighing 5-6 kg, and in prime condition. Before use, each animal received a complete eye examination to exclude any preexisting disease. The pupil responses, eye movements, ocular alignment, ocular media, and fundus were normal in every case. All procedures used in these experiments were approved by the Committee on Animal Research at University of California, San Francisco.

Strabismus can be induced experimentally at any age. We chose to begin this avenue of research on strabismic suppression by testing adult animals. Our ultimate goal is to understand the phenomenon of suppression in children. However, before investing the effort required to raise infant monkeys with strabismus, it seemed best to see whether promising results could be obtained first in strabismic adults. In Discussion we consider this issue further and compare the mechanisms of suppression in adults and children.

We induced strabismus by tenotomy of the medial rectus muscle in both eyes. The procedure was performed under general anesthesia with ketamine $\mathrm{HCl}(15 \mathrm{mg} / \mathrm{kg}$, i.m.) and topical proparacaine $\mathrm{HCl}$. After the muscle was released, the insertion site was examined carefully to ensure that the tendon was severed completely. Afterward, topical antibiotic ointment was applied liberally to the eyes. The animals were checked every day after the operation to verify rapid healing and to observe ocular alignment.

Once each animal had developed a stable, divergent strabismus, it was fasted for $12 \mathrm{hr}$ and placed in a restraining chair to measure ocular alignment in primary gaze. Two methods were used to gauge the magnitude of the exotropia. The first relied on decentration of the corneal light reflex in one eye (Hirschberg test), estimated while the monkey fixated a small, handheld point light source held $60 \mathrm{~cm}$ away. Grapes were used to attract the animal's attention and to win its cooperation. Each millimeter of light reflex decentration was equivalent to $14^{\circ}$ of ocular deviation (Quick and Boothe, 1989). For the second method, we determined the magnitude of a base-in prism required to center the corneal light reflex in each eye (Krimsky test). The Hirshberg and Krimsky tests were done by several examiners to arrive at a consensus regarding the magnitude of each animal's primary exodeviation. For documentation, photographs were also taken at a distance of $60 \mathrm{~cm}$ with a ring-flash mounted on the end of a $100 \mathrm{~mm}$ macro lens.

Fixation preference was judged independently by each author, as well as by two pediatric ophthalmologists. Assessments were made by watching each animal's spontaneous behavior and by testing its fixation preference while reaching for food treats. Frequent observations of unrestrained animals in their home cages were recorded by each examiner over several weeks. Examiners were asked to decide whether the animal had a fixation preference for one eye. If so, the examiner rated the preference as strong or weak. An animal with a strong fixation pattern spent $>80 \%$ of the time foveating with its preferred eye. An animal with a weak fixation pattern spent only $60-80 \%$ of the time looking with its preferred eye. Estimates were verified by reviewing videotapes of the animals. Observational assessment of fixation preference is simple and quite accurate when done by experienced strabismologists (Choi and Kushner, 1998).

Between 4-8 weeks after inducing strabismus, we labeled the ocular dominance columns in each monkey by $\left[{ }^{3} \mathrm{H}\right]$ proline transneuronal autoradiography. The tracer injection was always made into the eye that the monkey used preferentially for fixation. It was prepared by reconstituting $2 \mathrm{mCi}$ of L-[2,3,4,5- $\left.{ }^{3} \mathrm{H}\right]$ proline (specific activity, $102-106 \mathrm{Ci} / \mathrm{mmol}$; Amersham, Arlington Heights, IL) in $20 \mu \mathrm{l}$ of sterile balanced salt solution. The pupil was dilated pharmacologically, and the eye was massaged gently to lower the intraocular pressure below $12 \mathrm{mmHg}$. The tracer was then injected through the pars plana into the midvitreous of the eye under anesthesia with ketamine $\mathrm{HCl}(10 \mathrm{mg} / \mathrm{kg}$ i.m.) and topical proparacaine $\mathrm{HCl}$. Immediately afterward, the fundus was checked with an indirect ophthalmoscope for any sign of injury. The survival time for transport of the label was 7-9 d. Just before perfusion, the eye was examined again with an indirect ophthalmoscope. In each animal, the eye appeared unscathed by injection of the radioisotope.

Histological procedures. After receiving a lethal injection of sodium pentobarbital into the peritoneal cavity, each monkey was perfused through the left ventricle with 11 of normal saline followed by 11 of $2 \%$ paraformaldehyde in $0.1 \mathrm{M}$ phosphate buffer. Flat-mounts of striate cortex were prepared from each hemisphere (Horton and Hocking, 1996c), cut with a freezing microtome, mounted on slides, and air-dried. 
Alternating sections were reacted for CO (Wong-Riley, 1979) or dipped into NTB-2 emulsion (Eastman Kodak, Rochester, NY) for autoradiography. The autoradiographs were exposed for 10 weeks and developed with D19 developer (Kodak) (Wiesel et al., 1974). In three animals the lateral geniculate bodies were sectioned and reacted for $\mathrm{CO}$.

Data Analysis. Cortical CO flat mounts were imaged at 600 dots per inch on an Agfa (Mortsel, Belgium) Arcus II flatbed scanner fitted with a transparency adapter. To compare regions at higher power, $\mathrm{CO}$ sections and autoradiographs were photographed through an Olympus (Tokyo, Japan) SZH10 microscope using Technical Pan film (Kodak). Negatives were processed with D19 developer and scanned into the computer using a Microtek (Redondo Beach, CA) Scanmaker 35t scanner. Images were imported into Photoshop 5.0 (Adobe Systems, San Jose, CA) to prepare illustrations. Measurements were made using Scion Image PC (Scion Corp., Frederick, MD).

In a previous paper, we used a series of neutral density filters to calibrate the optical density of each CO section (Horton and Hocking, 1998a). This approach allowed us to compare the absolute density of CO reaction product between sections and between animals. In this present study, the $\mathrm{CO}$ patterns were often quite subtle. To improve their visibility, we found it necessary to adjust the brightness and contrast of each section. For this reason, the images in this paper were not calibrated to optical density standards.

\section{RESULTS}

\section{Induction of strabismus}

The day after surgery, all the monkeys had a huge divergent strabismus measuring $\sim 60^{\circ}$. In each case the exotropia showed marked spontaneous improvement in the first 2 weeks after surgery (Sireteanu et al., 1993). The mechanism was unclear, but the animals may have learned to reduce lateral rectus muscle tone in each eye. In addition, postmortem examination showed some adhesion of Tenon's capsule and the intermuscular septum at the site of the medial rectus tendon insertion. Although the muscle itself did not reinsert, it may have exerted some tension through these capsular attachments.

After the first few weeks, reduction of the exotropia became more gradual. Some monkeys improved more than others, with final deviations ranging between 8 and $25^{\circ}$. Although convergent strabismus is more prevalent clinically, we deliberately made all our monkeys exotropic, because we were concerned that esotropic monkeys with small deviations might fuse near targets. With exotropia, even if a monkey had only a small deviation, we were sure that its eyes were misaligned all the time. None of our exotropic monkeys appeared able to use accommodative convergence to fuse intermittently.

In five of six monkeys, a fixation preference emerged within a few days of surgery. Because the monkeys could not fully adduct their eyes, they usually made a slight head turn to the opposite side to fixate with each eye. To switch fixation, the monkeys bobbed their heads back and forth. This behavior became less striking as the exotropia diminished and the ocular motility improved. Even when subtle, it made it easy to see when the animals switched fixation. In one animal, observers did not agree on the eye fixation preference. It did not seem worthwhile to study this animal, given that we were unsure of its eye preference. Therefore, it was donated to another laboratory. The remaining five animals achieved a stable exotropia by $4-8$ weeks after surgery, and observers agreed unanimously on their ocular fixation preference. Figure 2 shows each animal before $\left[{ }^{3} \mathrm{H}\right]$ proline injection into the preferred eye, $\sim 10 \mathrm{~d}$ before perfusion. Intraocular injection of $\left[{ }^{3} \mathrm{H}\right]$ proline did not affect the magnitude of the exotropia or the eye fixation preference in any monkey.
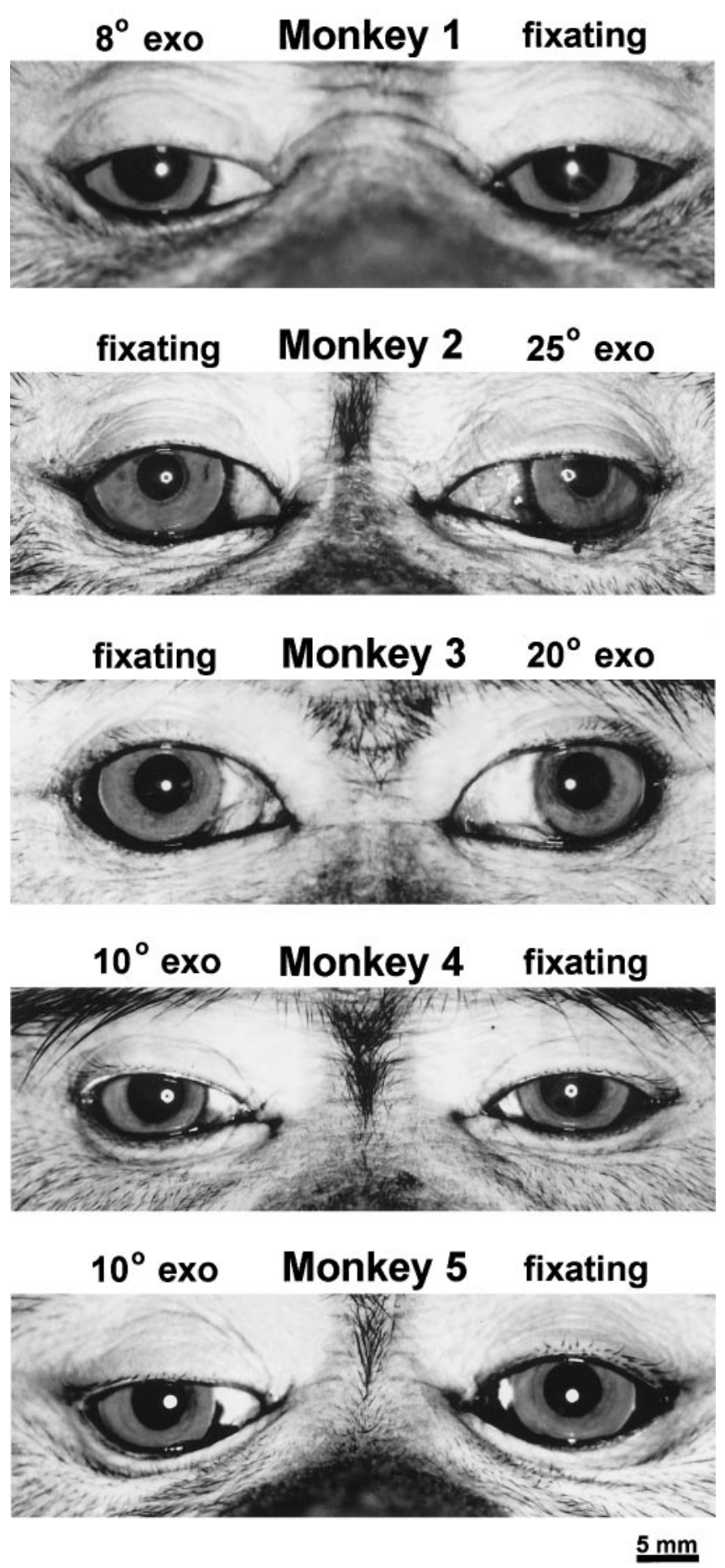

Figure 2. Photographs of the five macaques that developed a clear eye preference, showing decentration of the corneal light reflex (Hirshberg test) from a ring-flash mounted on a macro lens $60 \mathrm{~cm}$ away. Each millimeter of displacement corresponds to $\sim 14^{\circ}$. The magnitude of each animal's exotropia in primary gaze was determined by combining estimates made by at least two examiners using the Hirshberg test and the Krimsky test. Although each animal underwent the same operation (bilateral medial rectus tenotomy), the final deviations varied considerably.

\section{Monkey 1 (right exotropia, $8^{\circ}$ )}

This animal developed the smallest exodeviation, measuring only $8^{\circ}$, but all observers concurred that it had a strong preference for the left eye, fixating with it virtually all the time. $\left[{ }^{3} \mathrm{H}\right]$ Proline was 

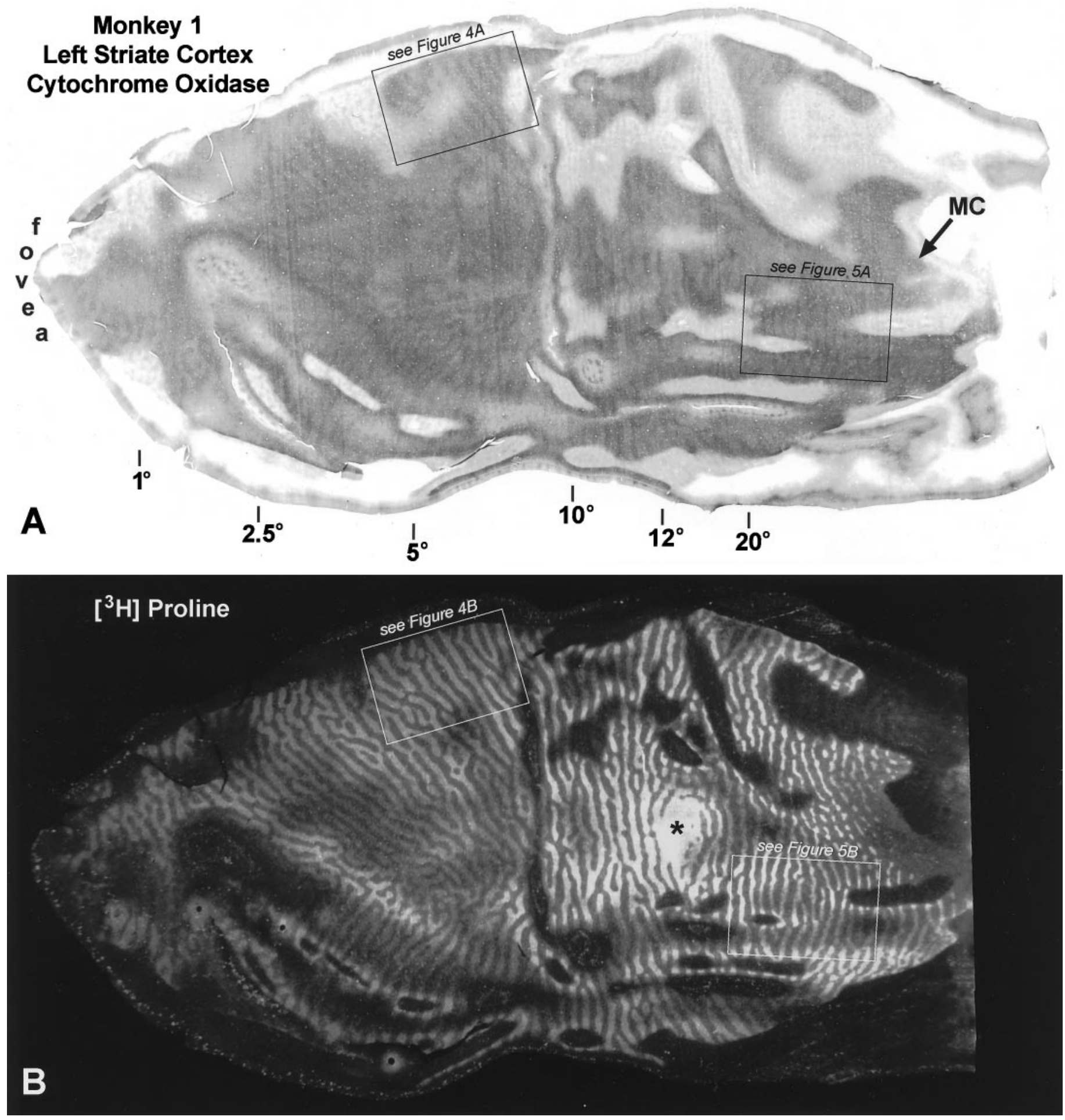

Figure 3. Monkey 1 ( $8^{\circ}$ right exotropia). $A, C$, Single $\mathrm{CO}$ sections passing mostly through layer IVc, showing a faint pattern of alternating light and dark columns induced by strabismus. They resemble the columns seen after monocular eyelid suture. The visual field eccentricities marked below the section are based on the cortical maps of Daniel and Whitteridge (1961), Van Essen et al. (1984), and Tootell et al. (1988). The lateral half of each section, representing the central $8^{\circ}$, is exposed on the smooth, posterior surface of the occipital lobe and is referred to as "opercular cortex" or "the operculum." The boxed regions are shown at higher power in subsequent figures, as indicated. $B, \mathrm{D}$, Autoradiographs of single sections immediately superficial to the $\mathrm{CO}$ sections above, showing the ocular dominance columns labeled by $\left[{ }^{3} \mathrm{H}\right]$ proline injection into the fixating left eye. In dark-field illumination, the labeled ocular dominance columns appear bright. In peripheral cortex, between the representations of the blind spot $(*)$ and the monocular crescent $(M C)$, the ocular dominance columns serving the ipsilateral eye become attenuated, reducing cortical binocularity.

(Figure continues.) 

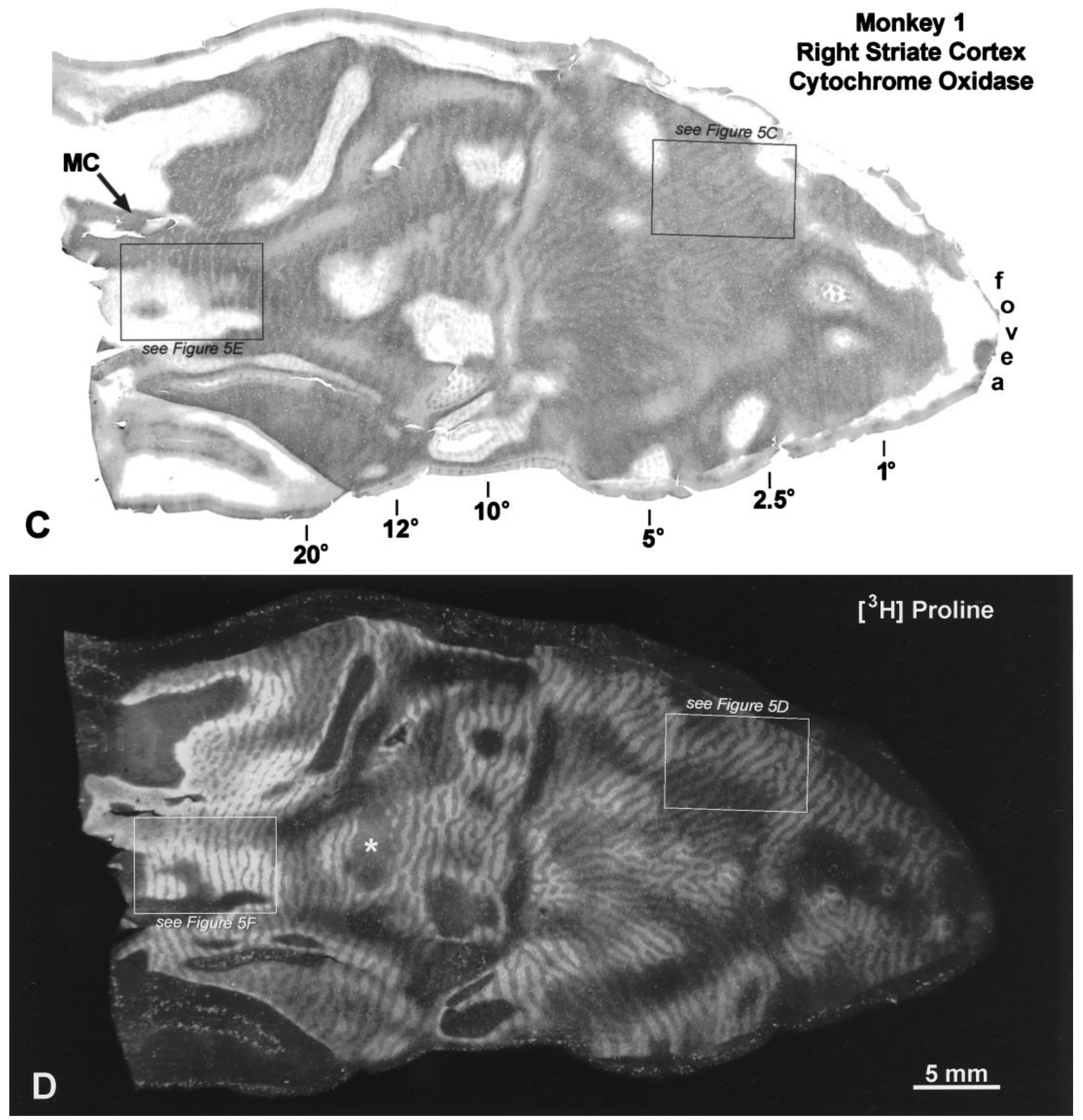

Figure 3. Continued.

injected into the left eye 4 weeks after eye muscle surgery, followed by perfusion $9 \mathrm{~d}$ later. Figure $3, A$ and $C$, shows single $\mathrm{CO}$-stained tangential sections cut through flat-mounts of the left and right striate cortex. The sections pass mostly through layer $\mathrm{IVc}$, revealing the $\mathrm{CO}$ pattern in that layer over a wide expanse of cortex, representing most of the visual field. In animals with normal ocular alignment and visual acuity, no pattern of $\mathrm{CO}$ activity is seen in layer IVc (Horton, 1984). In this strabismic animal, a remarkable pattern of alternating dark and light $\mathrm{CO}$ columns was visible everywhere, following the general layout of the ocular dominance columns (LeVay et al., 1985). The columns were quite faint, resembling those seen after eyelid suture, rather than after enucleation (Horton and Hocking, 1998a).

Eyelid suture produces a low-contrast $\mathrm{CO}$ pattern of thin dark columns alternating with wide pale columns in layer IVc (Horton, 1984; Hendry and Jones, 1986; Crawford et al., 1989; Trusk et al., 1990; Tigges et al., 1992). This pattern results from loss of CO activity in the sutured eye's monocular core zones and in both 

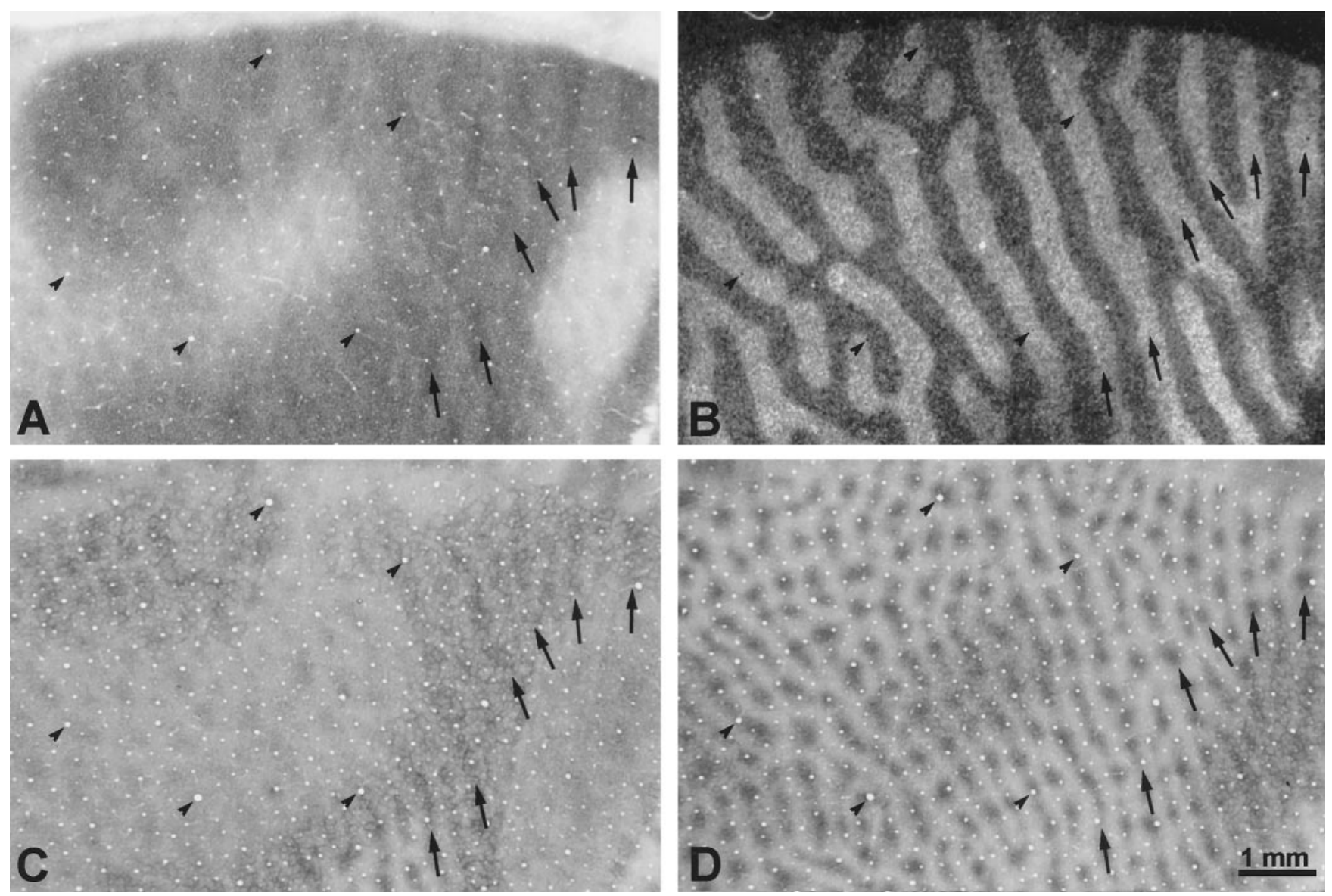

Figure 4. Monkey 1 ( $8^{\circ}$ right exotropia). $A$, Boxed region from layer IVc of the left operculum (Fig. $3 A$ ) showing the $\mathrm{CO}$ pattern at higher magnification. The arrows mark six thin dark columns. $B$, Corresponding region from Figure $3 B$, showing that the labeled ocular dominance columns (arrows) of the fixating left eye match the thin dark CO columns in $A$. The labeled ocular dominance columns are slightly thicker than the dark CO columns, but the difference is small, because it amounts only to the width of a pair of border strips ( $\sim 50 \mu \mathrm{m}$ in this animal). $C$, Section $330 \mu \mathrm{m}$ superficial to $A$, showing that strabismus has induced bands in the normally continuous honeycomb lattice of layer IVa. Every other band (arrows) is slightly darker, in register with the dark core zones in $A$. $D$, Section $405 \mu \mathrm{m}$ more superficial to $A$, showing rows of CO patches in layer III. They form more continuous rows than in normal monkeys, and the rows (arrows) in register with the dark core zones in $A$ are slightly darker. Examination of serial alternate sections showed that $\mathrm{CO}$ activity was greater in the core zones of the fixating left eye in all cortical layers except layer I. Arrowheads mark blood vessels used for aligning sections. All frames are to identical scale.

eyes' binocular border strips (Horton and Hocking, 1998a). We wondered whether strabismus might have induced the same effect in striate cortex. On close inspection of the opercular cortex in Figure 3, the dark columns looked slightly thinner than the pale columns. This impression was confirmed by measuring the width of 50 light columns and 50 dark columns, selected arbitrarily from each opercular cortex. The average widths were $297 \pm 51.3$ (SD) $\mu \mathrm{m}$ for the dark columns and $408 \pm 73.7 \mu \mathrm{m}$ for the light columns. Assuming that the dark columns represented the core zones of the fixating eye, a pair of border strips measured $55.5 \mu \mathrm{m}$, yielding for a single wide pale column $55.5+297+55.5=408 \mu \mathrm{m}$.

To interpret the CO pattern in Monkey 1 , it was vital to know its relationship to the ocular dominance columns. Figure $3, B$ and $D$, shows autoradiographs prepared from adjacent sections superficial to the $\mathrm{CO}$ sections illustrated in Figure 3, $A$ and $C$. Ocular dominance columns were visible throughout the section in layer IVc. On the operculum the ocular dominance columns were about equal in width. In the periphery, beyond the blind spot representation, the columns serving the ipsilateral eye became shrunken and fragmented, a normal feature described by LeVay et al. (1985).
To compare CO patterns with autoradiographs, one must examine local regions at high power, so that blood vessel patterns can be matched precisely to ensure accurate alignment of adjacent sections. Figure $4 A$ shows the $\mathrm{CO}$ pattern in layer IVc from the left operculum of Monkey 1 , in a region between 5 and $8^{\circ}$, near the lower vertical meridian. Figure $4 B$ shows the corresponding region from the adjacent autoradiograph. The thin dark $\mathrm{CO}$ columns match the proline-labeled ocular dominance columns, although they are slightly thinner, because they represent core zones only. In this region of cortex, we concluded that $\mathrm{CO}$ activity was richer in the core zones of the fixating eye.

This metabolic bias in layer IVc favoring the fixating eye was perpetuated through the full thickness of the cortex, implying that visual processing was affected in both afferent and efferent layers. Figure $4 C$ shows the $\mathrm{CO}$ pattern in layer IVa. Bands of label were present, with each band running down the middle of an ocular dominance column. In normal animals, bands are never found in layer IVa (Horton, 1984). Instead, one sees a continuous "honeycomb" of CO activity. Bands emerged in Monkey 1 because strabismus reduced metabolic activity within the border strips, sparing activity in the core zones. In addition, CO staining 

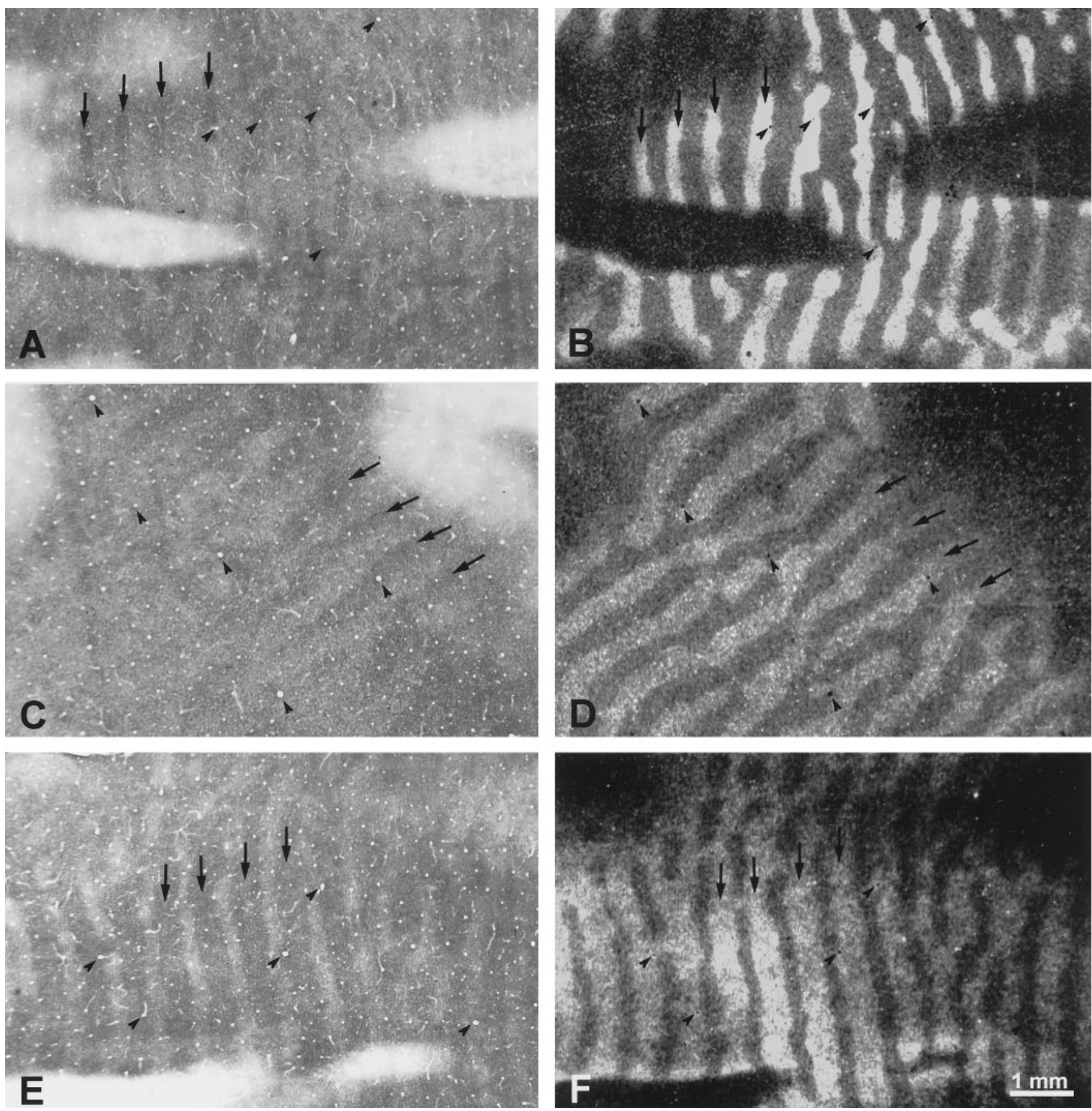

Figure 5. Monkey 1 ( $8^{\circ}$ right exotropia). $A, B$, Adjacent $\mathrm{CO}$ and proline sections from the left peripheral cortex (Fig. $\left.3 A, B\right)$. The autoradiograph is 70 $\mu \mathrm{m}$ deeper than the section illustrated in Figure $3 B$. The dark $\mathrm{CO}$ columns correspond to the left eye's labeled ocular dominance columns (compare arrows). $C, D$, Adjacent $\mathrm{CO}$ and proline sections from the right operculum (Fig. $3 C, D$ ), showing that the dark CO columns belong to the left eye (compare arrows). $E, F$, Adjacent $\mathrm{CO}$ and proline sections, each $70 \mu \mathrm{m}$ superficial to the sections shown in Figure $3, C$ and $D$, again showing a match between the dark CO columns and the left eye's ocular dominance columns, this time in the right peripheral cortex. In this animal, the dark CO columns were associated with the fixating left eye everywhere in striate cortex of both hemispheres.

appeared slightly darker in the core zones of the fixating eye (matching the dark core zones in layer IVc), giving rise to a pattern of alternating dark and light core zones in layer IVa, separated by pale gaps representing the border strips.

In layers II and III, the CO patches appeared almost to merge as they ran down the middle of the ocular dominance columns (Fig. 4D). This tendency for patches to form "pearls on a string" is seen in normal animals, but it was exaggerated in all our strabismic monkeys. Again, we believe that loss of $\mathrm{CO}$ activity in border strips accentuated each row of $\mathrm{CO}$ patches by silhouetting it against a paler $\mathrm{CO}$ background. Strabismus also caused the rows of patches in register with the core zones of the fixating left eye to appear slightly darker than the rows serving the deviating right eye. This effect was subtle but definite and even visible in layers V and VI. Therefore, metabolic hegemony of the fixating eye was evident in all cortical layers (except layer I). It is worth 

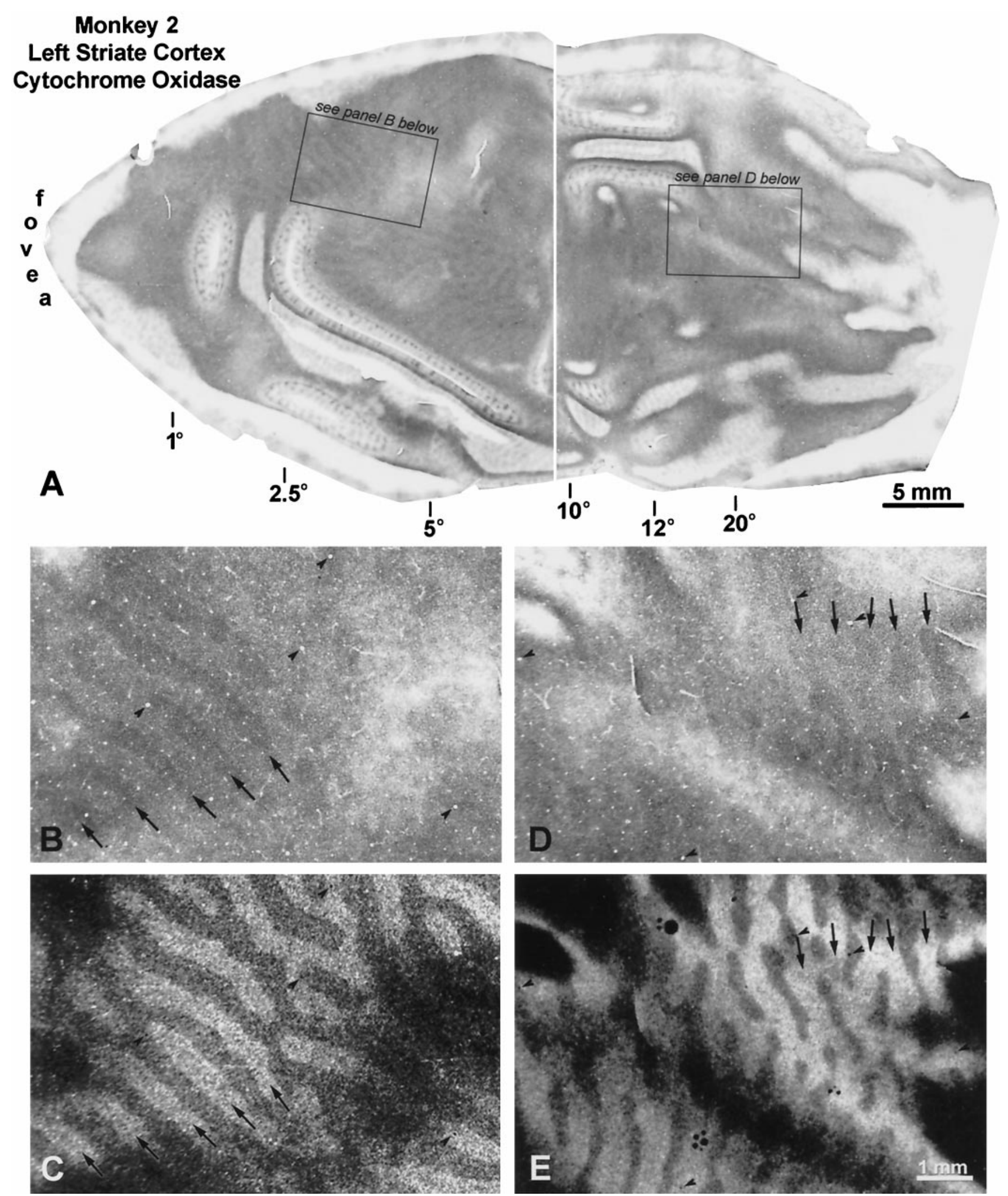

Figure 6. Monkey $2\left(25^{\circ}\right.$ left exotropia). A, A composite of two half-sections, $30 \mu \mathrm{m}$ apart, is shown to give the best view of the CO pattern in layer IVc of this animal. The thin white line running down the middle shows the section boundaries. On the left operculum, alternating thin dark and wide pale $\mathrm{CO}$ columns are visible in layer IVc. In the periphery, the wide pale columns become thinner than the dark columns, because the ipsilateral (left) eye's ocular dominance columns become shrunken in this region. $B$, Boxed region from $A$, showing the $\mathrm{CO}$ pattern at higher power. $C$, Region corresponding to $B$, from an adjacent autoradiograph, showing that the dark $\mathrm{CO}$ core zones match the fixating, injected right eye's ocular dominance columns (compare arrows), although, of course, they are slightly narrower. $D$, Boxed region, from peripheral cortex, showing the CO pattern. $E$, Adjacent autoradiograph, showing that the dark $\mathrm{CO}$ columns match label from the right eye. 

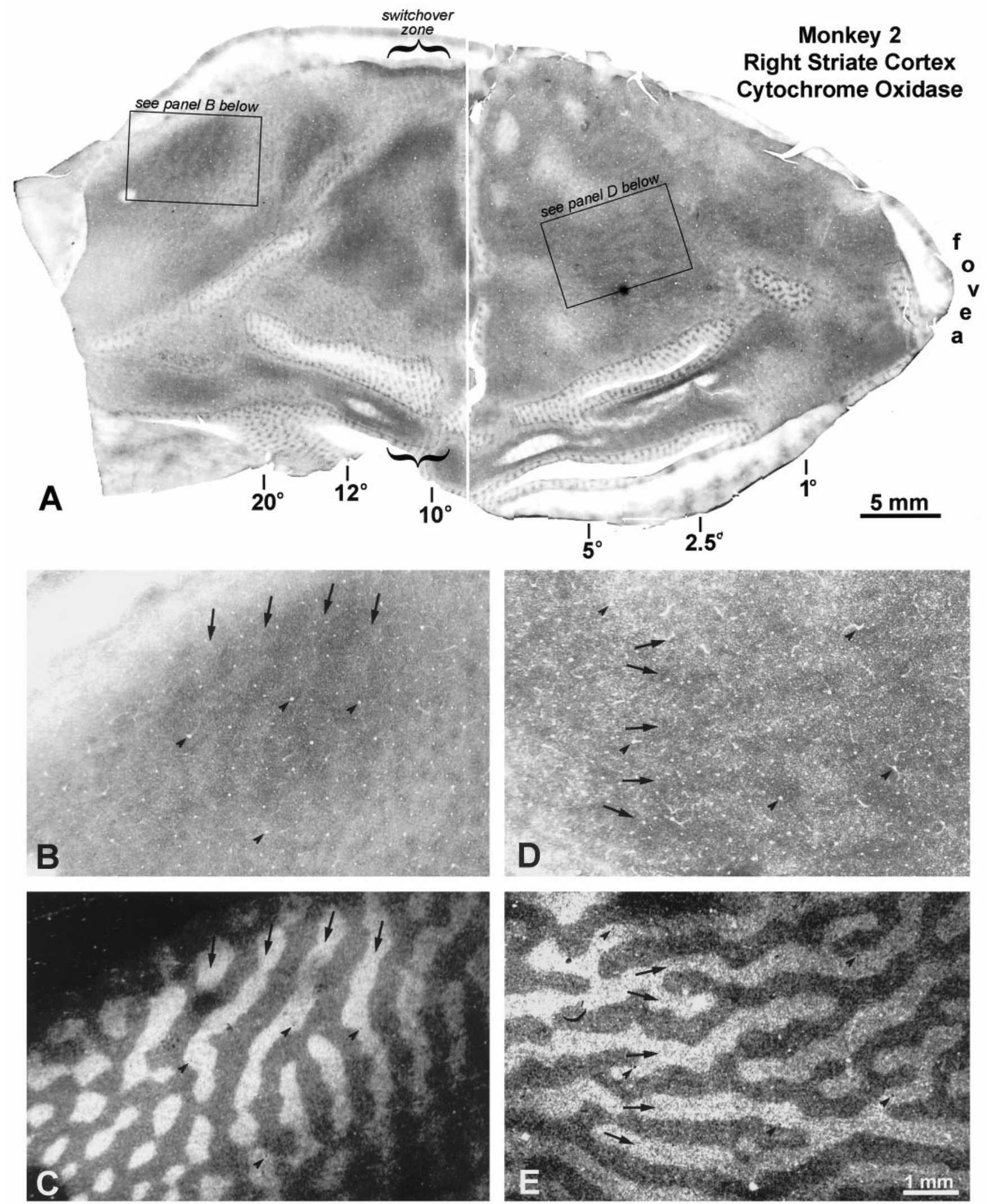

Figure 7. Monkey $2\left(25^{\circ}\right.$ left exotropia). A, Flat-mount composite of the right striate cortex, showing a faint pattern of CO columns in layer IVc. $B$, Boxed region from $A$, showing $\mathrm{CO}$ columns from 20 to $40^{\circ}$, near the lower vertical meridian. $C$, Matching region from an adjacent autoradiograph, showing that the pale $\mathrm{CO}$ columns correspond to the labeled ocular dominance columns of the right eye. In the right cortex, from the switchover zone to the monocular crescent, the deviating left eye was dominant metabolically. Everywhere else, the fixating right eye's ocular dominance columns had stronger $\mathrm{CO}$ activity. $D$, CO pattern in layer IVc of the right operculum. E, Matching region from an adjacent autoradiograph, showing that the dark $\mathrm{CO}$ columns correspond to the labeled ocular dominance columns of the right eye. 

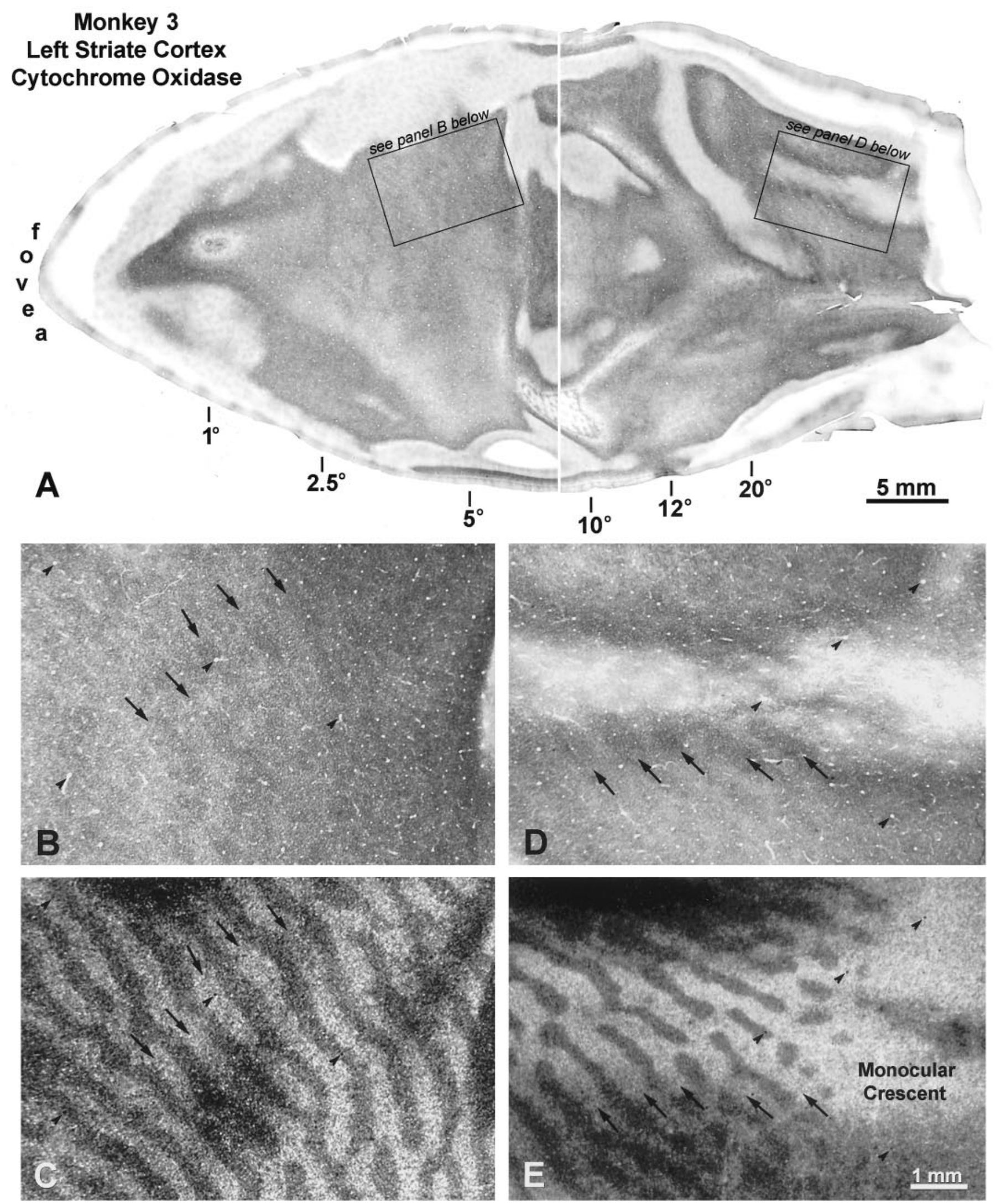

Figure 8. Monkey $3\left(20^{\circ}\right.$ left exotropia). A, Flat-mounts through layer IVc reveal alternating dark and light CO columns everywhere in the left striate cortex, which increase in contrast toward the representation of the periphery. $B$, Boxed region from the left operculum, showing faint pattern of thin dark core zones. $C$, Matching autoradiograph, showing that the dark $\mathrm{CO}$ core zones pictured above correspond to the labeled ocular dominance columns of the injected, fixating right eye. $D$, Boxed region from the left periphery, showing CO columns. $E$, Matching autoradiograph, demonstrating that the dark $\mathrm{CO}$ columns above correspond to the right eye. 

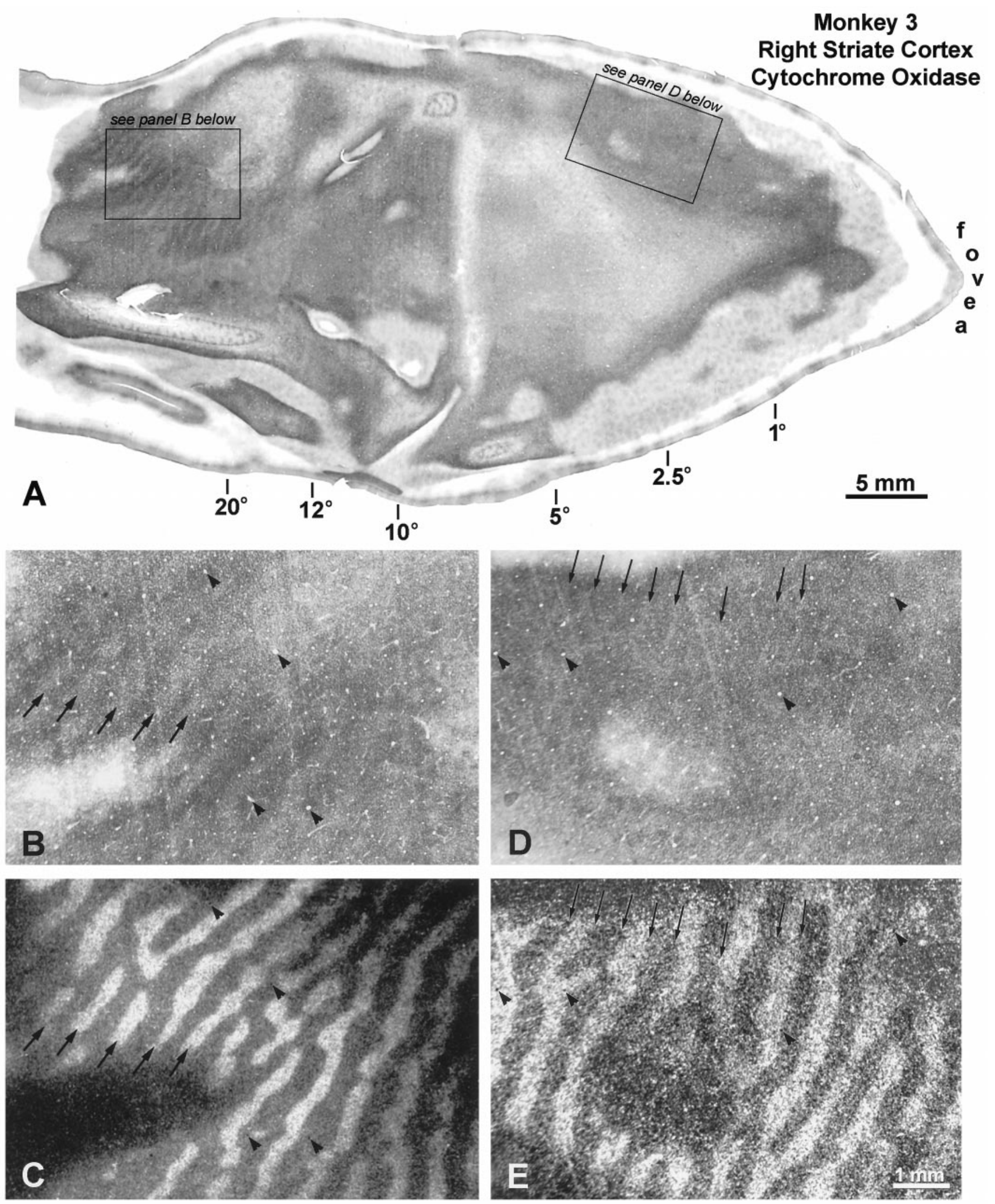

Figure 9. Monkey $3\left(20^{\circ}\right.$ left exotropia). A, Layer IVc of the right operculum contains a faint CO pattern of thin pale bands. In the periphery, a strong pattern of light and dark columns emerges. $B$, CO section from the periphery above, showing CO columns. $C$, Matching autoradiograph shows that the pale CO columns correspond to the labeled ocular dominance columns of the right eye (compare arrows). D, Arrows denote faint thin pale bands, $\sim 50-70$ $\mu \mathrm{m}$ wide, visible on the right operculum. They are partly obscured by knife scratches, which slant in the other direction. E, Matching autoradiograph, showing that the pale $\mathrm{CO}$ bands fall on the borders between ocular dominance columns. Therefore, they represent pairs of border strips, whose metabolic activity is reduced by strabismus. 

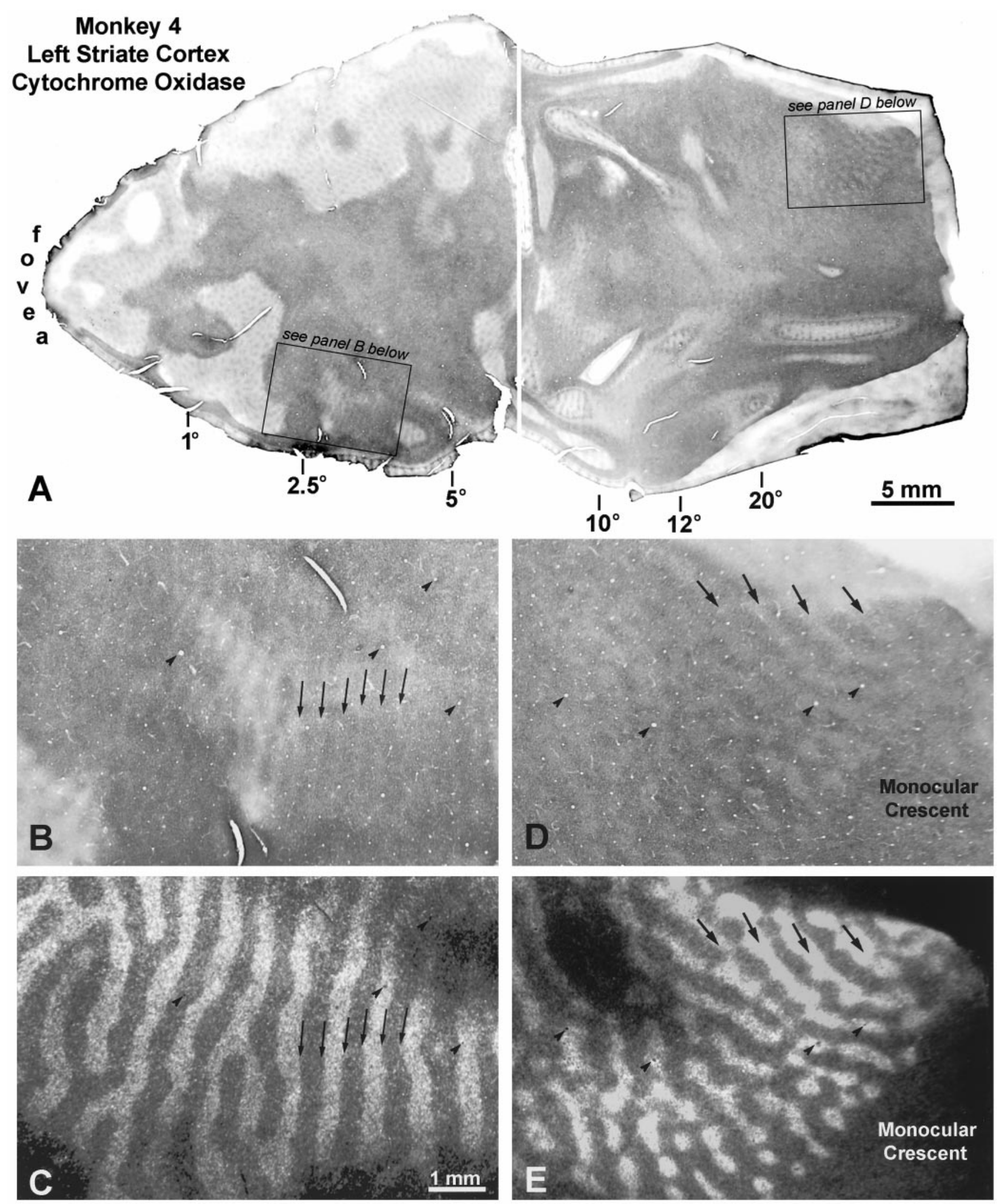

Figure 10. Monkey $4\left(10^{\circ}\right.$ right exotropia). A, Pale border strips are present everywhere on the operculum, whereas alternating dark and light columns appear in the periphery. $B$, High-power view, showing the pale border strips marked by arrows. $C$, Matching autoradiograph, verifying that the pale bands in $B$ straddle the borders of the ocular dominance columns. $D$, Close-up of the dark and light $C O$ columns in the periphery. Note that CO staining is dark in the monocular crescent representation, which receives an exclusive projection from the nasal retina of the right eye. E, Matching autoradiograph, showing that the pale CO columns correspond to the injected left eye's ocular dominance columns. In the periphery of the left visual cortex, therefore, the right eye was metabolically dominant, which is logical in divergent strabismus, because it corresponds to perceptual dominance of the right eye in the right peripheral visual field. 

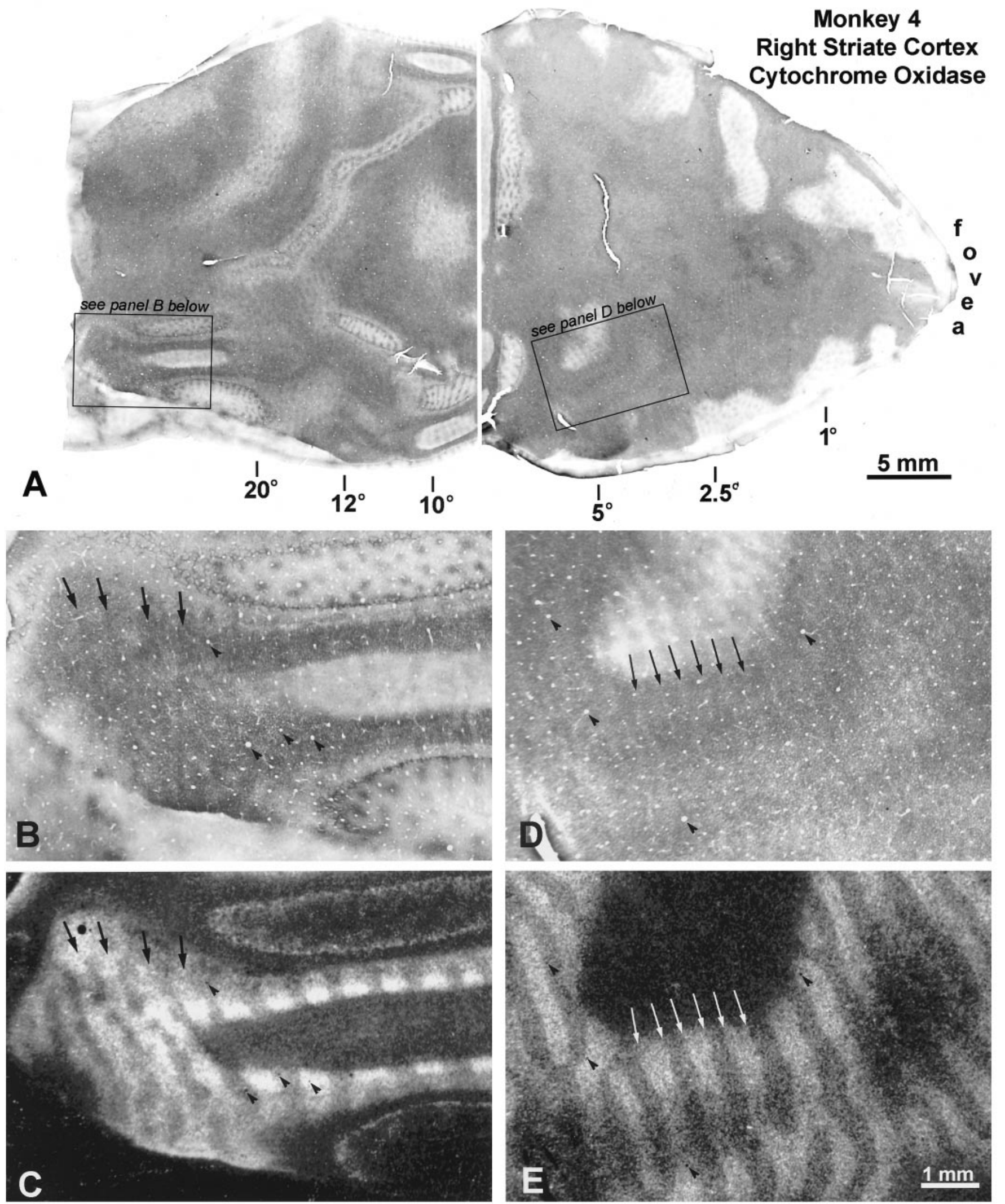

Figure 11. Monkey $4\left(10^{\circ}\right.$ right exotropia). A, As on the left side, pale border strips are visible throughout the right operculum. In the periphery, dark and light columns are present, although they are difficult to appreciate. $B$, High-power view of the right peripheral cortex, with arrows marking four dark $\mathrm{CO}$ columns. $C$, Autoradiograph, showing that the dark CO columns match the left eye's labeled ocular dominance columns. Thus, the left eye is dominant in the left peripheral visual field. $D$, High-power view of the opercular CO pattern, showing pale strips, which actually are seen best at lower power above. $E$, Autoradiograph, showing that the pale CO strips are border strips, because they are situated at the boundaries of ocular dominance columns (compare arrows). 
emphasizing that although strabismus mimicked the pattern produced by eyelid suture in layer IVc, outside layer IVc it yielded a lower-contrast pattern of light and dark rows of patches. Curiously, eyelid suture in adult monkeys induces a high-contrast pattern outside layer IVc, rivaling that seen after enucleation (Horton, 1984; Horton and Hocking, 1998a).

In Figure 4, CO patterns are compared with ocular dominance columns in only a small region of cortex. To confirm the assignment of the dark $\mathrm{CO}$ columns to the ocular dominance columns of the fixating left eye, we compared $\mathrm{CO}$ sections and autoradiographs throughout each striate cortex. Everywhere, the dark $\mathrm{CO}$ columns fit in register with the labeled ocular dominance columns. Figure 5 shows examples of three other regions matched at high power. Note that in the periphery of the right cortex (Fig. $5 E$ ), the $\mathrm{CO}$ pattern appeared as wide dark columns alternating with thin pale columns. This reversal occurred because, beyond $15^{\circ}$ (Fig. $5 F$ ), the ocular dominance columns serving the ipsilateral eye become naturally shrunken, whereas those serving the contralateral eye become expanded (LeVay et al., 1985). As a result, in the right peripheral cortex, the usual pattern of thin dark-wide pale columns was replaced by wide dark-thin pale columns (Fig. 5E). Parenthetically, it is worth noting that in peripheral cortex, the existence of well organized border strips is uncertain. Neurons with tuned disparity selectivity are more common in the central visual field representation, where binocular input is closely balanced (Poggio, 1995). In peripheral cortex, border strips may be rudimentary, because disparity-tuned cells are sparse, and ocular input is biased strongly in favor of the contralateral eye. If so, core zones may become nearly equivalent to ocular dominance columns, and $\mathrm{CO}$ patterns from strabismus may correspond almost exactly to the actual boundaries of ocular dominance columns.

To summarize the findings in Monkey 1, the fixating left eye had stronger metabolic activity throughout the left and right striate cortex. Even in the monocular crescent of the left cortex, where the deviating right eye did not have to compete with the fixating left eye, CO staining appeared pale. Metabolic activity in the deviating eye's ocular dominance columns was reduced globally, and the left eye was dominant everywhere in the cortex (and hence in the visual field).

\section{Monkey 2 (left exotropia, 25)}

This animal had the largest deviation, a left exotropia measuring $25^{\circ}$. All observers agreed that it had a strong right eye fixation preference. The right eye was injected with $\left[{ }^{3} \mathrm{H}\right]$ proline 6 weeks after induction of strabismus. As in Monkey 1, there were faint columns of $\mathrm{CO}$ activity everywhere in layer IVc of the left (Fig. $6 A$ ) and the right striate cortex (Fig. $7 A$ ). On the opercula, the dark columns were slightly thinner than the pale columns, consistent with loss of $\mathrm{CO}$ activity in border strips, and in the core zones of the deviating left eye. To check the assignment of the dark CO columns, they were compared at high power with adjacent autoradiographs. In the left cortex, the dark columns corresponded to the labeled ocular dominance columns of the fixating right eye, both on the operculum and in the periphery (Fig. $6 B-E)$. In the right cortex, the same result was found on the operculum (Fig. 7D,E). However, in peripheral cortex, the opposite was seen: the pale $\mathrm{CO}$ columns matched the labeled ocular dominance columns of the right eye (Fig. $7 B, C$ ). The most straightforward explanation for this result would be that the deviating left eye was suppressed everywhere, except in the peripheral right visual cortex (representing the left peripheral visual field). In this region it enjoyed perceptual dominance, and the right eye was locally suppressed. Note that the switchover occurred at an eccentricity of $10-12^{\circ}$ in the left visual cortex (Fig. $7 A$ ), which did not equal the magnitude of the divergent strabismus $\left(\sim 25^{\circ}\right)$. This means that the peripheral temporal retina of the fixating right eye was actively suppressed in favor of the nasal retina of the deviating left eye.

\section{Monkey 3 (left exotropia, 20 ${ }^{\circ}$ )}

This animal also had a left exotropia, but it was slightly smaller than the previous animal's exotropia. His fixation preference for the right eye was strong. $\left[{ }^{3} \mathrm{H}\right]$ Proline was injected into the right eye 4 weeks after the medial rectus tenotomies. On the operculum of the left visual cortex, there were alternating thin dark and wide pale $\mathrm{CO}$ columns in layer IVc, but they were quite faint (Fig. 8A). At high power, it was verified that the thin dark $\mathrm{CO}$ columns matched the ocular dominance columns of the fixating right eye (Fig. 8, compare $B, C$ ). In the periphery of the left cortex, the $\mathrm{CO}$ columns were higher in contrast. Again, the dark $\mathrm{CO}$ columns coincided with the ocular dominance columns of the dominant right eye (Fig. 8, compare $D, E$ ).

In the right visual cortex, from the representation of the fovea to $10^{\circ}$, the pattern of $\mathrm{CO}$ staining in layer IVc was extremely subtle (Fig. 9A). It appeared homogeneous, except for a faint pattern of parallel pale strips, $\sim 50-70 \mu \mathrm{m}$ wide, spaced about every half-millimeter. Comparison with adjacent autoradiographs showed that the pale strips ran right along the borders between ocular dominance columns (Fig. 9, compare $D, E$ ). We concluded that the pale strips corresponded to pairs of border strips. Their metabolic activity was reduced because binocularity was disrupted by strabismus. Only pale border strips were seen in the right operculum, because metabolic activity was equal in the core zones serving each eye.

In the peripheral right cortex, a clear pattern of dark and light $\mathrm{CO}$ columns emerged from $10^{\circ}$ to the monocular crescent representation (Fig. 9A). The more peripheral in the cortex, the greater the contrast of the columns. At high power, we found that the pale $\mathrm{CO}$ columns matched the ocular dominance columns of the injected, dominant right eye (Fig. 9, compare $B, C$ ). To summarize: in this monkey the fixating right eye was dominant throughout the left visual cortex; both eyes held equal sway on the right operculum; and the deviating left eye was supreme in the right peripheral cortex.

\section{Monkey 4 (right exotropia, $10^{\circ}$ )}

This monkey preferred to fixate with the left eye, but he alternated fixation frequently. All five observers rated his fixation preference as weak. A $\left[{ }^{3} \mathrm{H}\right]$ proline injection was made into the left eye 4 weeks after induction of strabismus. Figure 10 shows the pattern of $\mathrm{CO}$ activity in the left visual cortex. On the operculum, pale border strips were visible throughout layer IVc. In the periphery, beginning at $\sim 10^{\circ}$, alternating dark and pale columns emerged. Moving toward the monocular crescent representation, their contrast increased steadily. The pale $\mathrm{CO}$ columns matched the ocular dominance columns labeled by tracer from the preferred left eye.

In the right visual cortex the same pattern of $\mathrm{CO}$ activity was seen, but in reverse (Fig. 11). On the operculum, pale border strips were present. Beginning at $10^{\circ}$, a pattern of alternating dark and light $\mathrm{CO}$ columns began to appear. On this side, it was the dark CO columns that matched the labeled ocular dominance columns of the left eye. In this animal, therefore, the eyes had 


\section{Cytochrome Oxidase Strabismus Patterns}

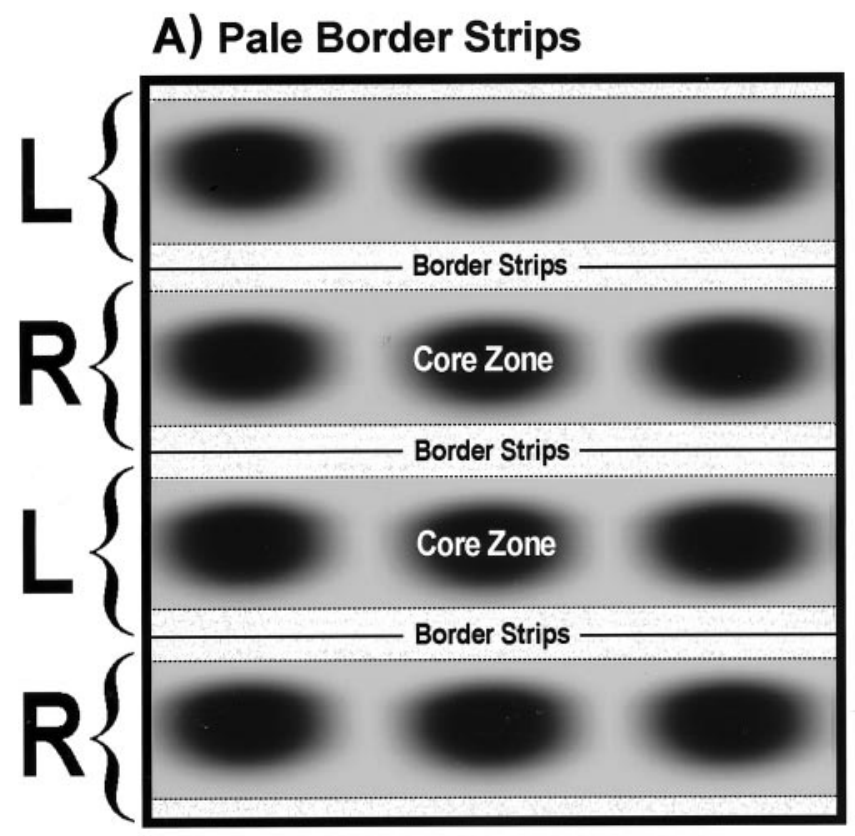

B) Thin Dark/Wide Pale Columns

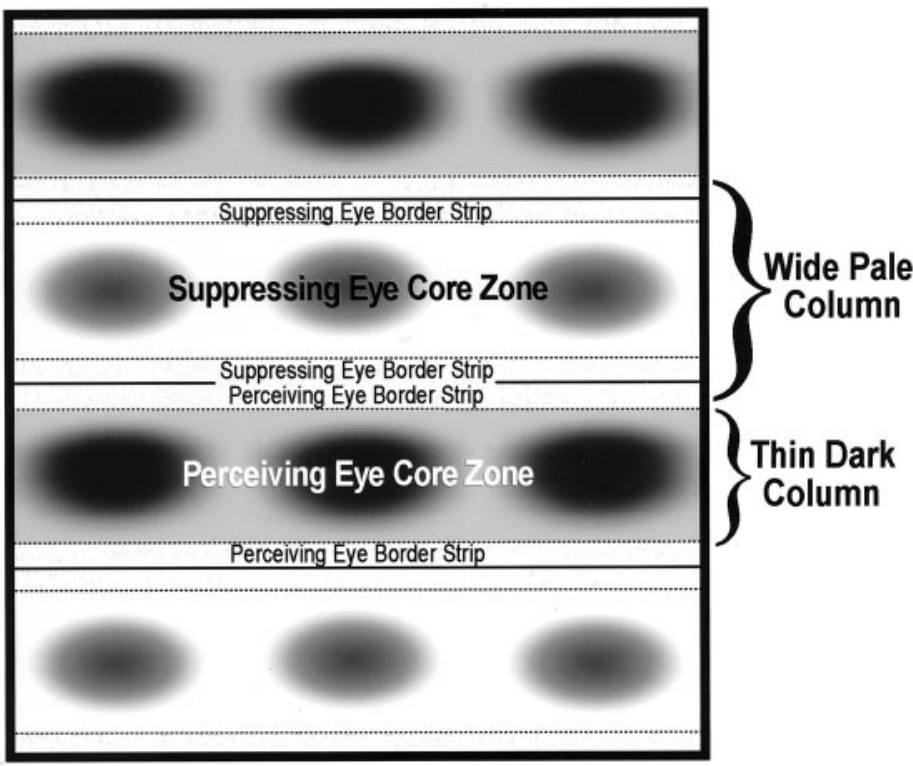

Figure 12. Schematic diagrams showing the two patterns of $\mathrm{CO}$ activity induced by strabismus. $A$, Pale border strips prevailed in regions of cortex where $\mathrm{CO}$ activity was lost in the binocular border strips, from disruption of ocular alignment, but metabolic activity remained strong in the monocular core zones serving each eye. This pattern was seen only in cortex representing the central $15^{\circ}$ and was most evident in the two monkeys with a weak fixation preference. $B$, Thin dark alternating with wide pale columns were seen in cortex where CO activity was reduced in both eyes' binocular border strips and one eye's monocular core zones. Presumably, $\mathrm{CO}$ was lowered in the suppressed eye's core zones. This pattern was seen throughout the cortex in animals with a strong fixation preference but only in the peripheral cortex of those with a weak fixation preference.

equal metabolic influence within the central field representation. Presumably the $\mathrm{CO}$ method was not sensitive enough to show a subtle bias in favor of the left eye, which one might have expected from the animal's weak fixation preference. The only sign of strabismus was the loss of $\mathrm{CO}$ activity within border strips. In the peripheral field representation, $\mathrm{CO}$ activity on each side was richer in ocular dominance columns serving the contralateral eye. This pattern of staining was consistent with suppression of the temporal retina in each eye, which, of course, would be expected in divergent strabismus.

\section{Monkey 5 (right exotropia, $10^{\circ}$ )}

The findings in this monkey are not illustrated, because they resembled closely those described in Monkey 4. The animal had a right exotropia of similar magnitude and a weak fixation preference for the left eye. The $\left[{ }^{3} \mathrm{H}\right]$ proline injection was made into the left eye 8 weeks after eye muscle surgery. On each operculum, a $\mathrm{CO}$ pattern of pale border strips was seen. In the periphery of each cortex, dark and pale $\mathrm{CO}$ columns were present. The dark columns coincided with the ocular dominance columns of the contralateral eye on each side. Therefore, as illustrated for Monkey 4, the temporal retina appeared to be suppressed in each eye of this animal.

\section{DISCUSSION}

The main finding in this study was that induction of strabismus produced an abnormal pattern of metabolic activity in primary visual cortex of macaques. In each animal, for example, we could identify regions of cortex where $\mathrm{CO}$ activity was greater in the dominant, fixating eye's ocular dominance columns. In these regions, we infer that neurons were less active within ocular dominance columns serving the deviating eye. The most logical interpretation would be that cortical activity driven by the deviating eye was suppressed to avoid diplopia and confusion. In the paragraphs below we outline the evidence in favor of this notion.

The first issue is whether suppression even occurs in adult subjects. Classically, it is taught that adults with acquired ocular misalignment can learn to ignore a troublesome second image but never exhibit true strabismic suppression (von Noorden, 1996, page 215). There is evidence from evoked potentials, however, for true suppression of cortical activity in adults with acquired strabismus (Wright et al., 1990). Some investigators have suggested that strabismic suppression may harness the same innate cortical mechanism that prevents diplopia under normal conditions of binocular rivalry (Franceschetti and Burian, 1971; Harrad et al., 1996), although this idea is controversial (Smith et al., 1985). If correct, the difference between suppression in children and adults may be simply that children can invoke suppression with greater facility. Until the mechanisms of strabismic suppression are better understood in both children and adults, it is probably best to keep an open mind on these questions. It is certainly worth comparing cortical CO patterns induced by strabismus in adults and children. Examination of young macaques raised with strabismus will be our next step.

Strabismus induced two different patterns of $\mathrm{CO}$ activity in layer IVc of opercular cortex. The first pattern consisted of slender pale bands, spaced every half-millimeter (Fig. 12A). By alignment with ocular dominance columns labeled by $\left[{ }^{3} \mathrm{H}\right]$ proline in adjacent sections, we showed that these pale bands represented pairs of border strips straddling the boundaries between ocular dominance columns. Strabismus caused selective loss of CO 
activity in the border strips because they are rich in binocular cells, which are generally excited maximally when driven by both eyes at a preferred disparity. A pattern of pale border strips, similar to that seen in strabismus, has also been found in newborn macaques (Horton and Hocking, 1996a). It probably occurs because ocular alignment and binocular function are immature in newborns (Chino et al., 1997). The pale border strips fade a few weeks after birth, around the time when stereopsis begins to emerge (O'Dell and Boothe, 1997). Weak CO staining along border strips has also been observed in a single adult macaque with mild amblyopia (Horton et al., 1997). This animal may have had a small angle strabismus that reduced $\mathrm{CO}$ activity within border strips.

The second $\mathrm{CO}$ pattern in layer IVc consisted of thin dark columns alternating with wide pale columns (Fig. 12B). It was generated by loss of $\mathrm{CO}$ activity in the border strips of both eyes and in the core zones of one eye. We believe that $\mathrm{CO}$ was lost in the core zones of the eye that was locally suppressed. The pattern induced by strabismus looked exactly like the pattern induced by monocular eyelid suture. From the point of view of $\mathrm{CO}$ activity, therefore, strabismic suppression had an effect tantamount to closure of one eye. It was, in metabolic terms, as if the brain achieved strabismic suppression by invoking a mechanism equivalent to local occlusion of one retina.

The abnormal CO patterns seen in the strabismic monkeys were faint, compared with the vivid columns seen after monocular enucleation, TTX injection, or retinal laser lesions (Horton, 1984; Wong-Riley and Carroll, 1984; Horton and Hocking, 1998a). These manipulations eliminate input from one eye, resulting in drastic reduction of $\mathrm{CO}$ activity within geniculate cell bodies and axon terminals, accounting for the high-contrast pattern seen in layer IVc. In three strabismic monkeys we examined $\mathrm{CO}$ staining in the lateral geniculate bodies. It was entirely normal. The CO patterns induced by strabismus, therefore, arose within the cortex. Although they were quite subtle (and difficult to illustrate), they were robust, in the sense that they were present everywhere in striate cortex of both hemispheres in all five animals.

Figure 13 summarizes the patterns of abnormal $\mathrm{CO}$ activity induced by strabismus in each monkey. It is important to remember that CO levels fluctuate over a time scale of days, not minutes or hours. At any given moment, the actual pattern of neuronal activity in any animal's cortex might have looked quite different from the staining pattern depicted in Figure 13. The CO pattern represents only the prevailing pattern of neuronal activity over 24-48 hr and cannot capture momentary fluctuations that occur from switches in fixation or attention. Although it is valuable to know the predominant pattern of cortical activation, it would also be exciting to explore the phenomenon of strabismic suppression using techniques with better time resolution. One could use electrophysiological recordings (or optical imaging) in awake, behaving monkeys (Thiele et al., 1997) or functional magnetic resonance imaging (fMRI) in humans. fMRI has poorer spatial resolution than $\mathrm{CO}$, but given the findings in this study, it should be quite easy to map regional suppression scotomas in striate cortex.

The monkeys in this study all had divergent strabismus, but a range of $\mathrm{CO}$ patterns was seen. Each pattern made sense, in terms of the animal's fixation behavior, which strengthens our hypothesis that it correlated with suppression in the visual field. Three monkeys had a strong fixation preference (Monkeys 1-3). Monkey 1 had darker $\mathrm{CO}$ staining in the fixating eye's ocular dominance columns everywhere in both cortices, implying complete suppression of the exotropic eye. Monkey 2 also had darker CO staining in the fixating eye's ocular dominance columns, except in the peripheral right cortex, where a switch took place in favor of the deviating left eye. This $\mathrm{CO}$ pattern signified perceptual dominance of the fixating right eye everywhere in the visual field, except in the left periphery. This is a common pattern of suppression in human exotropes (Melek et al., 1992). In Monkey 3, the $\mathrm{CO}$ pattern was similar, except that border strips were present on the right operculum. In this monkey, the temporal retina of the deviating left eye was entirely suppressed. The temporal retina of the fixating right eye was also suppressed, except for the temporal macula, where suppression alternated with the nasal macula of the left eye.

Monkeys 4 and 5 had weak fixation preferences. Not surprisingly, their cortical CO patterns revealed pale border strips in the central field representations bilaterally. Border strips may have appeared because their fixation preferences were too weak to produce a strong $\mathrm{CO}$ pattern favoring the dominant eye (i.e., thin dark-wide pale columns). Alternatively, the animals' central suppression scotomas may have shifted back and forth between the two eyes, without an actual change in fixation. Our methods could not distinguish between these two possibilities. Outside the maculae, the temporal retinas of both animals were suppressed, as one would expect in exotropia.

Studies of the visual fields in subjects with strabismus have documented a confusing range of findings, depending on the technique used to map suppression scotomas (Jampolsky, 1955; Pratt-Johnson and MacDonald, 1976; Sireteanu and Fronius, 1981; Sireteanu, 1982; Cooper and Record, 1986; Joosse et al., 1990, 1997; Melek et al., 1992). Mapping of the visual fields in strabismus is tricky, because one must dissociate the eyes enough to plot suppression scotomas, but not too much, or else they vanish. The conflicting results from various studies have been blamed on methodological differences (Mehdorn, 1989). It is also likely, judging from the range of $\mathrm{CO}$ patterns seen in our monkeys, that suppression scotomas vary widely in size, depth, and location, depending on the degree of ocular misalignment and the strength of fixation preference displayed by the subject. In general, clinical studies agree that the temporal retina is suppressed in exotropia (von Noorden, 1996). This finding prevailed in our monkeys.

Two other reports have described CO patterns in strabismic monkeys. Tychsen and Burkhalter (1997) reported "spontaneous" ocular dominance columns in an exotropic $M$. mulatta raised with daily alternate occlusion of one eye. No second label was used, so the CO pattern was difficult to interpret. In a second animal, a $M$. nemestrina with naturally occurring esotropia, wheat germ agglutinin-horseradish peroxidase (WGA-HRP) was injected into one eye to label the ocular dominance columns. Unfortunately, this tracer produces an intense uveitis, factitiously reducing $\mathrm{CO}$ activity in the injected eye's ocular dominance columns (Horton and Hocking, 1996b). Tychsen and Burkhalter reported that $\mathrm{CO}$ rich stripes corresponded to "nasal ODCs" (i.e., ocular dominance columns serving the contralateral eye) in both V1s, a result that cannot be attributed to damage from WGA-HRP injection. Their finding was consistent with the theory that functional dominance of the nasal retina contributes to esotropia (Tychsen and Lisberger, 1986) but was exactly opposite to the pattern of $\mathrm{CO}$ activity one would expect from regional suppression in convergent strabismus. Tychsen and Burkhalter (1997) did not illustrate both labels in the same region of cortex, so their 


\section{CO Activity in Strabismic Monkeys}

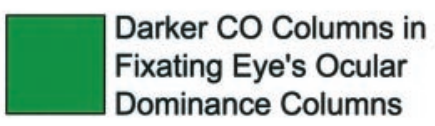

Dominance Columns
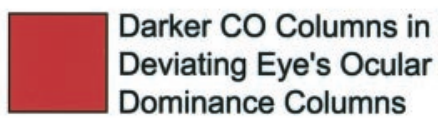

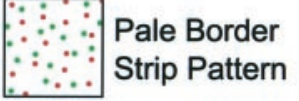

\section{Left Striate Cortex}
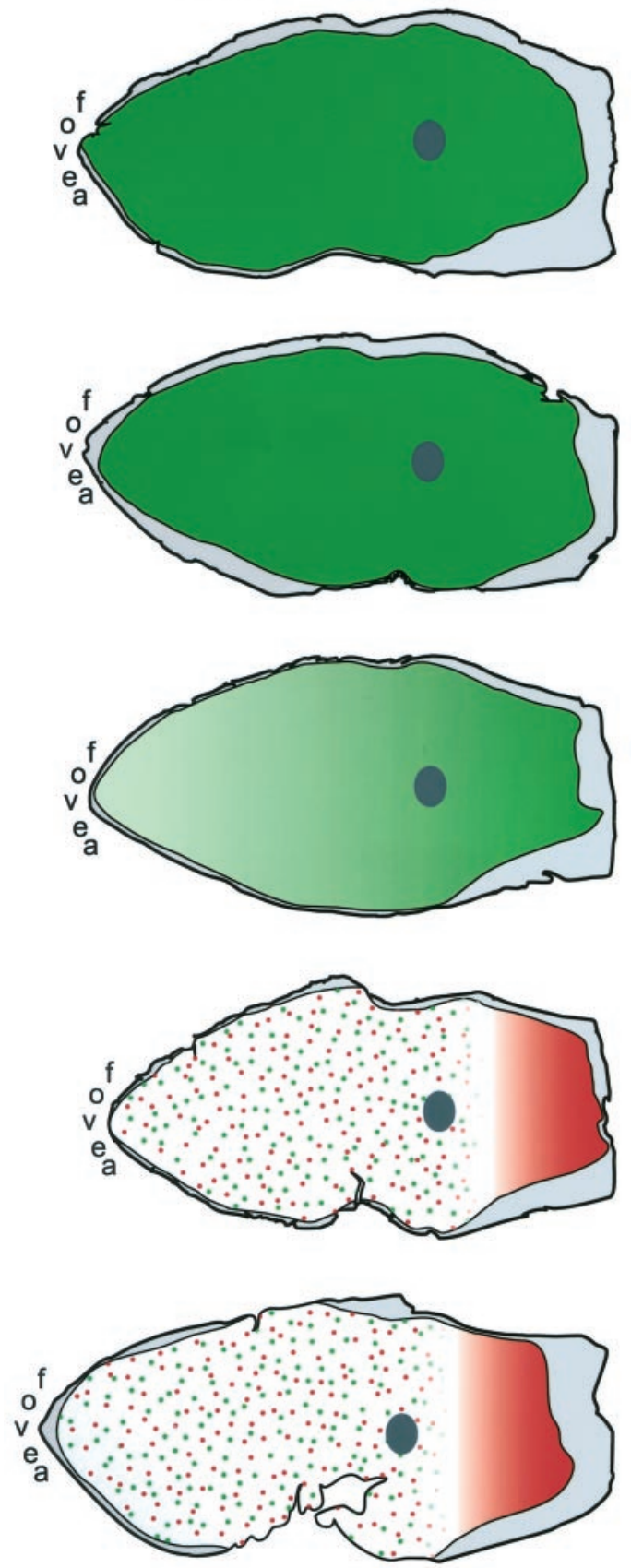

Monkey 1

Left Eye: Strongly Dominant Right Eye: $8^{\circ}$ Exotropic

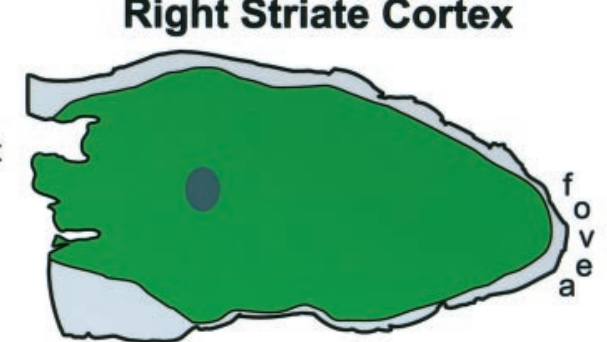

\section{Monkey 2 \\ Right Eye: Strongly Dominant Left Eye: $25^{\circ}$ Exotropic}
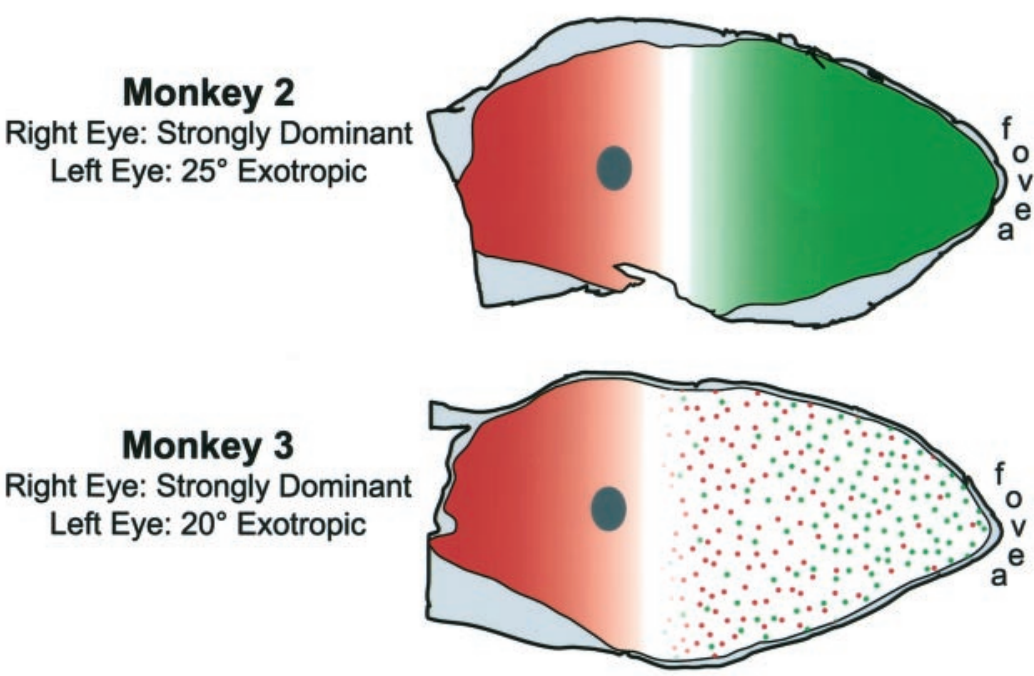

\section{Monkey 4 \\ Left Eye: Weakly Dominant Right Eye $10^{\circ}$ Exotropic}

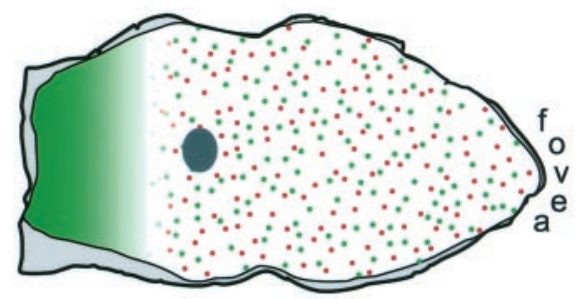

Monkey 5

Left Eye: Weakly Dominant Right Eye: $10^{\circ}$ Exotropic

$10 \mathrm{~mm}$

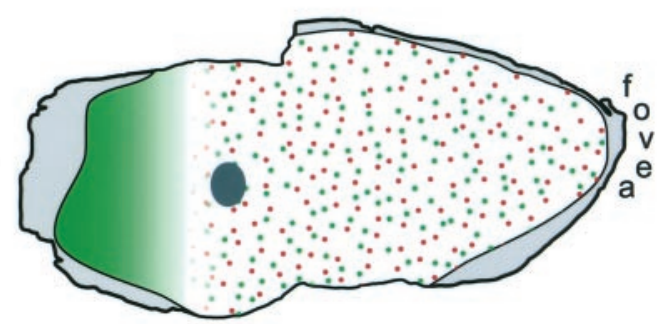

Figure 13. Summary diagram showing the CO patterns seen in striate cortex of each animal. The raw data are illustrated in Figures 3 and $6-11$, except for the last monkey. In cortex shaded green, the fixating eye was perceptually dominant most of the time in the visual field, and the chronically deviated eye was suppressed. In cortex shaded red, the reverse was true. This interpretation is based on the assumption that darker CO activity is present in ocular dominance columns serving the perceiving eye in any given region of cortex (whether or not that eye happens to be fixating). The patterns of suppression found in these animals are compatible with clinical data in human subjects with strabismus. These data show that in exotropes, the temporal retina is suppressed preferentially, as we found in four of five monkeys. In our monkeys, the pale border strip pattern, which occurred in cortex where both eyes perceived about equally, was always sandwiched between more peripheral cortex where opposite eyes dominated. This finding also supports our contention that these CO patterns are related to perceptual dominance of each eye in local portions of the visual field. The dark ovals are the blind spot "representations," which extend from 12 to $18^{\circ}$ along the horizontal meridian. 
experiment is difficult to assess, but it highlights the need for further studies of $\mathrm{CO}$ patterns in esotropia.

In a second report, Fenstemaker et al. (1997) examined CO staining in three monkeys with strabismic amblyopia. They found a pattern of alternating thin dark and wide pale columns, but paradoxically, the thin dark columns were thought to match the amblyopic eye's ocular dominance columns. This assignment was made by stimulating the amblyopic eye for $2 \mathrm{hr}$, while the monkey was still anesthetized at the end of a recording session, and then immunostaining alternate sections for the transcription factor EGR-1 (Zif-268) (Chauduri et al., 1995). It is possible that $2 \mathrm{hr}$ of visual stimulation were not enough to erase a preexisting EGR-1 bias in favor of the fixating eye's ocular dominance columns. EGR-1 patterns can linger long after stimulus conditions change, mandating caution when using this approach to assign $\mathrm{CO}$ columns to one eye or the other (Horton and Hocking, 1998a). That is why we elected to use $\left[{ }^{3} \mathrm{H}\right]$ proline as a second label in our experiments. Recently, we have used EGR-1 successfully, under different stimulus conditions, to show that darker $\mathrm{CO}$ staining is associated with the fixating eye in most of striate cortex (Horton and Hocking, 1998b).

Induction of strabismus in adults creates binocular rivalry. Leopold and Logothetis (1996) have reported that $\sim 20 \%$ of neurons in V1 and V2 of normal, trained monkeys modulates responses according to which eye is perceiving during binocular rivalry. An even greater percentage of neurons modulates activity in downstream visual areas such as V4. To explore further the issues raised by our findings, the best approach would be to map the visual fields dichoptically in strabismic monkeys. One could then record from single neurons to correlate changes in firing rates with switches in fixation, suppression scotomas, and cortical patterns of $\mathrm{CO}$ activity. This strategy could provide direct evidence that the $\mathrm{CO}$ patterns we have described in this report arise from perceptual suppression.

\section{REFERENCES}

Chaudhuri A, Matsubara JA, Cynader MS (1995) Neuronal activity in primate visual cortex assessed by immunostaining for the transcription factor Zif268. Vis Neurosci 12:35-50.

Chino YM, Smith III EL, Yoshida K, Cheng H, Hamamoto J (1994) Binocular interactions in striate cortical neurons of cats reared with discordant visual inputs. J Neurosci 14:5050-5067.

Chino YM, Smith III EL, Hatta S, Cheng H (1997) Postnatal development of binocular disparity sensitivity in neurons of the primate visual cortex. J Neurosci 17:296-307.

Choi RY, Kushner BJ (1998) The accuracy of experienced strabismologists using the Hirschberg and Krimsky tests. Ophthalmology 105:1301-1306.

Cooper J, Record CD (1986) Suppression and retinal correspondence in intermittent exotropia. Br J Ophthalmol 70:673-676.

Crawford MLJ, de Faber J-T, Harwerth RS, Smith III EL, von Noorden GK (1989) The effects of reverse monocular deprivation in monkeys II. Electrophysiological and anatomical studies. Exp Brain Res $74: 338-347$.

Crewther SG, Crewther DP (1993) Amblyopia and suppression in binocular cortical neurones of strabismic cat. NeuroReport 4:1083-1086.

Daniel PM, Whitteridge D (1961) The representation of the visual field on the cerebral cortex in monkeys. J Physiol (Lond) 159:203-221.

DeYoe EA, Trusk TC, Wong-Riley MTT (1995) Activity correlates of cytochrome oxidase-defined compartments in granular and supragranular layers of primary visual cortex of the macaque monkey. Vis Neurosci 12:629-639.

Fenstemaker SB, George, KH, Kiorpes L, Movshon JA (1997) Tangential organization of eye dominance in area V1 of macaques with strabismic amblyopia. Soc Neurosci Abstr 23:920.16.

Franceschetti A, Burian HM (1971) Visually evoked responses in alternating strabismus. Am J Ophthalmol 71:1292-1297.
Freeman RD, Tsumoto T (1983) An electrophysiological comparison of convergent and divergent strabismus in the cat: electrical and visual activation of single cortical cells. J Neurophysiol 49:238-253.

Goodhill GJ (1993) Topography and ocular dominance: a model exploring positive correlations. Biol Cybern 69:109-118.

Graefe A (1896) Das Sehen der Schielenden. Eine ophthalmologischphysiologische Studie. Wiesbaden, Germany.

Harrad R, Sengpiel F, Blakemore C (1996) Physiology of suppression in strabismic amblyopia. Br J Ophthalmol 80:373-377.

Hendry SHC, Jones EG (1986) Reduction in number of immunostained GABAergic neurones in deprived-eye dominance columns of monkey area 17. Nature 320:750-753.

Horton JC (1984) Cytochrome oxidase patches: a new cytoarchitectonic feature of monkey visual cortex. Philos Trans R Soc Lond B Biol Sci 304:199-253.

Horton JC, Hocking DR (1996a) An adult-like pattern of ocular dominance columns in striate cortex of newborn monkeys prior to visual experience. J Neurosci 16:1791-1807.

Horton JC, Hocking DR (1996b) Anatomical demonstration of ocular dominance columns in striate cortex of the squirrel monkey. J Neurosci 16:5510-5522.

Horton JC, Hocking DR (1996c) Intrinsic variability of ocular dominance column periodicity in normal macaque monkeys. $\mathrm{J}$ Neurosci 16:7228-7239.

Horton JC, Hocking DR (1998a) Monocular core zones and binocular border strips in primate striate cortex revealed by the contrasting effects of enucleation, eyelid suture, and retinal laser lesions on cytochrome oxidase activity. J Neurosci 18:5433-5455.

Horton JC, Hocking DR (1998b) Experimental strabismus reduces metabolic activity in ocular dominance columns serving the deviated eye. Soc Neurosci Abstr 24:105.5.

Horton JC, Hocking DR, Kiorpes L (1997) Pattern of ocular dominance columns and cytochrome oxidase activity in a macaque monkey with naturally occurring anisometropic amblyopia. Vis Neurosci 14:681-689.

Hubel DH, Wiesel TN (1965) Binocular interaction in striate cortex of kittens reared with artificial squint. J Neurophysiol 28:1041-1059.

Jampolsky A (1955) Characteristics of suppression in strabismus. Arch Ophthalmol 54:683-696.

Joosse MV, Wilson JR, Boothe RG (1990) Monocular visual fields of macaque monkeys with naturally occurring strabismus. Clin Vision Sci 5:101-111.

Joosse MV, Simonsz HJ, van Minderhout HM, de Jong PTVM, Noordzij B, Mulder PGH (1997) Quantitative perimetry under binocular viewing conditions in microstrabismus. Vision Res 37:2801-2812.

Leopold DA, Logothetis NK (1996) Activity changes in early visual cortex reflect monkeys' percepts during binocular rivalry. Nature 379:549-553.

LeVay S, Connolly M, Houde J, Van Essen DC (1985) The complete pattern of ocular dominance stripes in the striate cortex and visual field of the macaque monkey. J Neurosci 5:486-501.

Löwel S (1994) Ocular dominance column development: strabismus changes the spacing of adjacent columns in cat visual cortex. J Neurosci 14:7451-7468.

Löwel S, Singer W (1992) Selection of intrinsic horizontal connections in the visual cortex by correlated neuronal activity. Science 255:209-212.

Mehdorn E (1989) Suppression scotomas in primary microstrabismus - a perimetric artefact. Doc Ophthalmol 71:1-18.

Melek N, Shokida F, Dominguez D, Zabalo S (1992) Intermittent exotropia: a study of suppression in the binocular visual field in 21 cases. Binocul Vis Strabismus Q 7:25-30.

O'Dell C, Boothe RG (1997) The development of stereoacuity in infant rhesus monkeys. Vision Res 37:2675-2684.

Poggio GF (1995) Mechanisms of stereopsis in monkey visual cortex. Cereb Cortex 3:193-204.

Pratt-Johnson JA, MacDonald AL (1976) Binocular visual field in strabismus. Can J Ophthalmol 11:37-41.

Quick MW, Boothe RG (1989) Measurement of binocular alignment in normal monkeys and in monkeys with strabismus. Invest Ophthalmol Vis Sci 30:1159-1168.

Sengpiel F, Blakemore C (1994) Interocular control of neuronal responsiveness in cat visual cortex. Nature 368:847-850.

Sengpiel F, Blakemore C, Kind PC, Harrad R (1994) Interocular suppression in the visual cortex of strabismic cats. J Neurosci 14:6855-6871. 
Sireteanu R (1982) Binocular vision in strabismic humans with alternating fixation. Vision Res 22:889-896.

Sireteanu R, Fronius M (1981) Naso-temporal asymmetries in human amblyopia: Consequence of long-term interocular suppression. Vision Res 21:1055-1063.

Sireteanu R, Singer W, Fronius M, Greuel JM, Best J, Fiorentini A, Bisti S, Schiavi C, Campos E (1993) Eye alignment and cortical binocularity in strabismic kittens: a comparison between tenotomy and recession. Vis Neurosci 10:541-549.

Smith III EL, Levi DM, Manny RE, Harwerth RS, White JM (1985) The relationship between binocular rivalry and strabismic suppression. Invest Ophthalmol Vis Sci 26:80-87.

Smith III EL, Chino YM, Ni J, Cheng H, Crawford MLJ (1997) Residual binocular interactions in the striate cortex of monkeys reared with abnormal binocular vision. J Neurophysiol 78:1353-1362.

Thiele A, Bremmer F, Ilg UJ, Hoffmann KP (1997) Visual responses of neurons from areas V1 and MT in a monkey with late onset strabismus: a case study. Vision Res 37:853-863.

Tigges M, Boothe RG, Tigges J, Wilson JR (1992) Competition between an aphakic and an occluded eye for territory in striate cortex of developing rhesus monkeys: cytochrome oxidase histochemistry in layer 4C. J Comp Neurol 316:173-186.

Tootell RBH, Switkes E, Silverman MS, Hamilton SL (1988) Functional anatomy of macaque striate cortex. II. Retinotopic organization. J Neurosci 8:1531-1568.

Trusk TC, Kaboord WS, Wong-Riley MTT (1990) Effects of monocular enucleation, tetrodotoxin, and lid suture on cytochrome-oxidase reactivity in supragranular puffs of adult macaque striate cortex. Vis Neurosci 4:185-204.
Tychsen L, Burkhalter A (1995) Neuroanatomic abnormalities of primary visual cortex in macaque monkeys with infantile esotropia: preliminary results. J Pediatr Ophthalmol Strabismus 32:323-328.

Tychsen L, Burkhalter A (1997) Nasotemporal asymmetries in V1: ocular dominance columns of infant, adult, and strabismic macaque monkeys. J Comp Neurol 388:32-46.

Tychsen L, Lisberger SG (1986) Maldevelopment of visual motion processing in humans who had strabismus with onset in infancy. J Neurosci 6:2495-2508.

Van Essen DC, Newsome WT, Maunsell JHR (1984) The visual field representation in striate cortex of the macaque monkey: asymmetries, anisotropies, and individual variability. Vision Res 24:429-448.

von Noorden GK (1996) Binocular vision and ocular motility. Theory and management of strabismus, Ed 5. St. Louis: Mosby.

Wiesel TN, Hubel DH, Lam DMK (1974) Autoradiographic demonstration of ocular-dominance columns in the monkey striate cortex by means of transneuronal transport. Brain Res 79:273-279.

Wong-Riley M (1979) Changes in the visual system of monocularly sutured or enucleated kittens demonstrable with cytochrome oxidase histochemistry. Brain Res 171:11-28.

Wong-Riley MTT (1994) Primate visual cortex: dynamic metabolic organization and plasticity revealed by cytochrome oxidase. In: Cerebral cortex (Peters A, Rockland KS, eds), pp 141-200. New York: Plenum.

Wong-Riley M, Carroll EW (1984) Effect of impulse blockage on cytochrome oxidase activity in monkey visual system. Nature 307:262-264.

Wright KW, Fox BES, Eriksen KJ (1990) PVEP evidence of true suppression in adult onset strabismus. J Pediatr Ophthalmol Strabismus 27:196-201. 